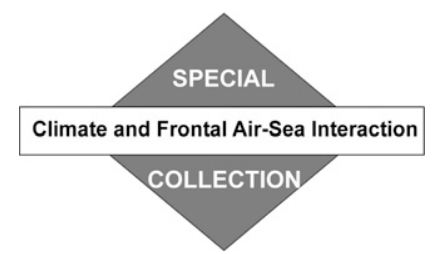

\title{
Response of Surface Wind Divergence to Mesoscale SST Anomalies under Different Wind Conditions
}

\author{
A. FOUSSARD \\ LMD/IPSL, CNRS, Ecole Polytechnique, Ecole Normale Supérieure, Sorbonne Université, Paris, and Ecole des \\ Ponts ParisTech, Champs-sur-Marne, France \\ G. LAPEYRE AND R. PlougOnVEN \\ LMD/IPSL, CNRS, Ecole Polytechnique, Ecole Normale Supérieure, Sorbonne Université, Paris, France
}

(Manuscript received 24 July 2018, in final form 26 April 2019)

\begin{abstract}
The response of the atmospheric boundary layer to mesoscale sea surface temperature (SST) is often characterized by a link between wind stress divergence and downwind SST gradients. In this study, an idealized simulation representative of a storm track above a prescribed stationary SST field is examined in order to determine in which background wind conditions that relationship occurs. The SST field is composed of a midlatitude large-scale frontal zone and mesoscale SST anomalies. It is shown that the divergence of the surface wind can correlate either with the Laplacian of the atmospheric boundary layer temperature or with the downwind SST gradient. The first case corresponds to background situations of weak winds or of unstable boundary layers, and the response is in agreement with an Ekman balance adjustment in the boundary layer. The second case corresponds to background situations of stable boundary layers, and the response is in agreement with downward mixing of momentum. Concerning the divergence of the wind stress, it generally resembles downwind SST gradients for stable and unstable boundary layers, in agreement with past studies. For weak winds, a correlation with the temperature Laplacian is, however, found to some extent. In conclusion, our study reveals the importance of the large-scale wind conditions in modulating the surface atmospheric response with different responses in the divergences of surface wind and wind stress.
\end{abstract}

\section{Introduction}

Satellite measurements have shown evidence of a local response of the atmospheric boundary layer to oceanic mesoscale structures (ranging from tens to hundreds of kilometers). It takes the form of a positive correlation between wind stress and sea surface temperature (SST) anomalies at all latitudes (Xie 2004). Equivalent relationships exist with correlation of divergence of the wind stress with along-wind SST gradient, or wind stress curl and across-wind SST gradient (Chelton et al. 2001, 2004; O'Neill et al. 2003). It was also revealed through the signature of ocean eddies in turbulent air-sea fluxes of sensible and latent heat (Bourras et al. 2004), or in cloud cover and rain rates (Frenger et al. 2013).

The coupling between the atmosphere and narrow oceanic structures has been explored through various

\footnotetext{
Corresponding author: G. Lapeyre, glapeyre@lmd.ens.fr
}

analyses of the horizontal momentum budget in the boundary layer based on theoretical models (Samelson et al. 2006; Schneider and Qiu 2015) or idealized simulations (Spall 2007; Kilpatrick et al. 2014, 2016). The general setting of these analyses was a large-scale wind blowing across (or along) an SST gradient, potentially leading to a change in the stability of the boundary layer. In locally unstable conditions (i.e., winds blowing from cold to warm waters), an increase of the downward transfer of momentum explains the correlation of wind or wind stress with SST anomalies (Wallace et al. 1989; Hayes et al. 1989). The mechanism of downward momentum mixing (DMM) was proposed to explain the relation between the divergence of wind stress and downwind SST gradients (e.g., Chelton et al. 2001; O'Neill et al. 2003).

Another mechanism that is considered in the literature is related to surface pressure variations induced by SST structures. It was initially proposed as an important 
source of coupling at tropical latitudes (Lindzen and Nigam 1987), and more recently as an important forcing for surface wind convergence over midlatitude SST fronts (Feliks et al. 2004; Minobe et al. 2008). The mechanism is based on a thermal adjustment of the boundary layer to the underlying SST, which creates local variations of the hydrostatic pressure. Through a mechanism in terms of Ekman balance mass adjustment (EBMA), the divergence of the surface wind correlates with the Laplacian of sea level pressure. The latter is itself very close to the Laplacian of the atmospheric temperature if the boundary layer has adjusted to the underlying SST, which is more likely for weak winds (Brachet et al. 2012; Lambaerts et al. 2013).

At midlatitudes, the importance of the pressure term compared to vertical mixing still remains unclear, largely depending on the spatial scales (Small et al. 2008) but also on the region of interest (Shimada and Minobe 2011) or on the season that is considered (Takatama et al. 2015). Moreover, the two mechanisms can be active together to force a surface divergence response. For instance, in the Kuroshio Extension region, Putrasahan et al. (2013) show that the divergence of wind stress correlates with downwind SST gradients (see their Fig. 4). At the same time, divergence of surface wind correlates with the Laplacian of SST (see their Fig. 7).

Most past studies have examined the time-average response (at least weekly averages) or the transient response (a few hours) of the atmospheric boundary layer to SST anomalies. As pointed out by Liu and Zhang (2013), O'Neill et al. (2017), or Plougonven et al. (2018), the responses differ when considering averaged or transients fields. Here, our goal is to determine the nature of the surface divergence response to mesoscale SST perturbations separating between classes of different large-scale wind conditions. For that purpose, we use an idealized simulation of an atmospheric storm track above a frontal SST zone including a variety of oceanic structures of horizontal scales from 40 to $400 \mathrm{~km}$.

Section 2 presents the configuration of the model with a brief description of the simulated storm track. We then document in section 3 the surface divergence response at the oceanic eddy scale by a composite analysis, and we show that the simulations are consistent with observational results such as those of Frenger et al. (2013). Section 4 describes the spatial organization of the boundary layer response, investigating how the response mechanisms change for different synoptic wind configurations. Differences between the responses in wind divergence and wind stress divergence are also investigated. Section 5 summarizes the results of the previous sections and compares them with previous studies.

\section{Model description}

\section{a. General configuration}

The 3.6.1 version of the WRF Model (Skamarock et al. 2008) is used to simulate a characteristic midlatitude storm track above a prescribed SST field. The model integrates the nonhydrostatic compressible moist Euler equations. Microphysics is represented with the Kessler (1969) scheme, and convection with the Kain and Fritsch (1993) scheme. The model uses the Yonsei University (YSU) parameterization (Hong et al. 2006) for the atmospheric boundary layer in conjunction with a Monin-Obukhov parameterization for surface layers (MM5 scheme). We do not include the effect of ocean surface currents in the wind stress calculation although it is known to affect the atmospheric boundary layer above oceanic eddies (Renault et al. 2016; Takatama and Schneider 2017).

The Cartesian domain, periodic in the zonal direction $x$, is of size $L_{x} \times L_{y}=9216 \mathrm{~km} \times 9216 \mathrm{~km}$. Horizontal resolution is set to $18 \mathrm{~km}$, and $50 \eta$ levels are used for the hydrostatic pressure vertical coordinate, equally spaced in pressure. Top pressure is set to $36 \mathrm{hPa}$, corresponding to an altitude of approximately $20 \mathrm{~km}$, and 13 levels are below $2 \mathrm{~km}$ of altitude. Free-slip boundary conditions are used at the poleward and equatorial walls of the domain, and $y=0$ corresponds to the equatorial side of the domain. A spatially varying Coriolis parameter is used with a largest $\beta$ effect in the center of the domain. Typical values of these parameters correspond to $40^{\circ} \mathrm{N}$ (see appendix A).

The model is forced by using a gray radiation scheme with an atmosphere transparent to water vapor and clouds, as proposed by Frierson et al. (2006). This forcing allows us to mimic simple relaxation forcings on dry variables (e.g., Held and Suarez 1994), but with the sole dependence on the SST field. The details of the radiative scheme are described in appendix B.

\section{b. Oceanic forcing}

We prescribe the sea surface temperature field, stationary in time and composed of a large-scale meridional gradient and an eddying component:

$$
\operatorname{SST}(x, y)=\overline{\operatorname{SST}}(y)+\underbrace{e^{-\left(y-y_{\text {sst }}\right)^{2} / l_{0}^{2}} F(x, y)}_{\operatorname{SST}_{\text {eddy }}(x, y)} .
$$

The large-scale front is described by

$$
\overline{\operatorname{SST}}(y)=\operatorname{SST}_{\mathrm{eq}}-\frac{\operatorname{SST}_{\mathrm{eq}}-\operatorname{SST}_{\mathrm{pol}}}{2}\left[1+\tanh \left(\frac{y-y_{\mathrm{sst}}}{l_{\mathrm{sst}}}\right)\right],
$$

with parameters defined in Table 1. SST ranges from $\mathrm{SST}_{\mathrm{pol}}=275 \mathrm{~K}$ to $\mathrm{SST}_{\mathrm{eq}}=295 \mathrm{~K}$ and is characterized 
TABLE 1. Common parameters.

\begin{tabular}{ll}
\hline \hline$\left(L_{x}, L_{y}\right)$ & $(9216,9216) \mathrm{km}$ \\
$\left(\mathrm{SST}_{\mathrm{eq}}, \mathrm{SST}_{\mathrm{pol}}\right)$ & $(295,275) \mathrm{K}$ \\
$y_{\mathrm{sst}}$ & $4500 \mathrm{~km}$ \\
$\left(l_{\mathrm{sst}}, l_{0}, l_{\beta}\right)$ & $(1000,1500,1500) \mathrm{km}$ \\
$f_{0}$ & $9.35 \times 10^{-5} \mathrm{~s}^{-1}$ \\
$\beta_{\max }$ & $1.75 \times 10^{-11} \mathrm{~m}^{-1} \mathrm{~s}^{-1}$ \\
$\Delta \theta$ & $10 \mathrm{~K}$ \\
$\left(D_{\mathrm{eq}}, D_{\mathrm{pol}}\right)$ & $(6,1.5)$ \\
$p_{0}$ & $10^{5} \mathrm{~Pa}$ \\
\hline
\end{tabular}

by a smooth transition between warm and cold waters with an SST gradient on the order of $1 \mathrm{~K}(100 \mathrm{~km})^{-1}$.

The eddying component $\operatorname{SST}_{\text {eddy }}(x, y)$ is obtained from a snapshot of a 2D turbulent field $F(x, y)$ of a surface quasigeostrophic (SQG) model (Lapeyre and Klein 2006) run for a domain size of $L_{x} / 2 \times L_{y} / 2$ and extended by periodicity to the full domain. The SQG model was shown to adequately represent the upperocean dynamics at mesoscale [see review of Lapeyre (2017).] The field $F(x, y)$ is normalized to get a standard deviation of $1.1 \mathrm{~K}$, and its zonal average is set to zero. Then it is multiplied with a Gaussian envelope to obtain the field $\mathrm{SST}_{\text {eddy }}$ located where the meridional large-scale gradient of SST is the most intense.

Figure 1 shows the total SST field and the corresponding SST anomalies. The maximum value of $\left|\mathrm{SST}_{\text {eddy }}\right|$ is $5.0 \mathrm{~K}$, but mesoscale SST anomalies have a relatively moderate signature in the total SST field, which is characterized by a frontal region between $y \approx 3000$ and $6000 \mathrm{~km}$ (Fig. 1a). These anomalies display a variety of structures with mesoscale eddies of various diameters, as well as long and thin filaments of $\sim 50-\mathrm{km}$ width attached to them (Fig. 1b; see also Fig. 5).

\section{c. Mean state of the troposphere}

A first simulation using $\overline{\text { SST }}$ as surface boundary condition was run for 4 years. Starting from its final state, a new simulation was then integrated over 8 years using the SST defined in (1). Outputs are saved twice a day, and the first three months are discarded as a spinup period when computing statistics. The dynamical equilibrium obtaining by taking a time and zonal average is presented on Fig. 2.

A typical storm track forms as a response to the largescale forcing: a tropospheric jet is located around $y=$ $6000 \mathrm{~km}$ with a maximum speed larger than $25 \mathrm{~m} \mathrm{~s}^{-1}$ around $\mathrm{p}=250 \mathrm{hPa}$. The height of the tropopause changes from $200 \mathrm{hPa}$ on the equatorial side of the domain down to $400 \mathrm{hPa}$ on the poleward side (not shown). The eddy poleward heat flux is maximum in the free troposphere at the center of the domain between $\mathrm{y}=$ 4000 and $6000 \mathrm{~km}$, while the eddy kinetic energy has its maximum slightly poleward at $y=5500 \mathrm{~km}$ (not shown). The simulated storm track is weaker than the Southern Hemisphere storm track for which the zonal jet reaches values of $35 \mathrm{~m} \mathrm{~s}^{-1}$ but has realistic features of midlatitudes baroclinic zones. A more detailed analysis of the response of the storm track to the oceanic mesoscale SST field is carried out in Foussard et al. (2019).

\section{Composite analysis at the oceanic eddy scale}

To assess the consistency of our idealized simulations with the observed relation between surface variables and SST anomalies, we first discuss the main features of the response of the atmospheric boundary layer to a typical mesoscale eddy. To that end, composites for cold and warm eddies are computed in the line of Park et al. (2006) or Frenger et al. (2013). For the sole purpose of identifying the position of the eddies, we use a method based on a wavelet packet decomposition [see details in Lapeyre and Klein (2006) and Doglioli et al. (2007)]. The procedure is to decompose $\mathrm{SST}_{\text {eddy }}$ in elementary wavelets of compact support (using the Haar basis). Then wavelet coefficients smaller than a given value are filtered out. The field that is recomposed with the remaining wavelets is such that it is zero at a given point if it does not belong to an eddy. This allows us to determine the precise location of each structure in order to compute the composites. The amplitude of an eddy is defined as the spatial average of the SST anomaly over the set of grid points within the eddy. The coordinates of its center are defined as their averaged values, and the eddy radius is defined as $R_{\text {eddy }}=\sqrt{\mathscr{C} / \pi}$, with $\mathscr{b}$ the area of the eddy (defined as the set of points belonging to the specific eddy). Only eddies with amplitude larger than $2 \mathrm{~K}$ are retained. This results in 16 warm and 16 cold eddies, with radii ranging from 81 to $145 \mathrm{~km}$ (see Fig. 1b).

For each eddy and each instantaneous snapshot, the large-scale background wind is defined as the average of the $10-\mathrm{m}$ wind within a square box of width equal to 10 radii centered on each eddy. This yields a direction (used for the rotation of different quantities) and an amplitude (used to separate strong- and weak-wind conditions). For presentation of the composites, all fields, including sea surface temperature, are rotated so that the large-scale wind blows toward $x>0$, and are translated so that the eddy center is at $(x, y)=(0,0)$. No spatial filtering has been applied to create the composites. Derivatives and Laplacian are computed using physical coordinates before rotation and translation are made. At the end, spatial coordinates are rescaled in units of eddy radii $R_{\text {eddy }}$. Composites of surface wind speed (10-m winds) and SST created through this procedure 

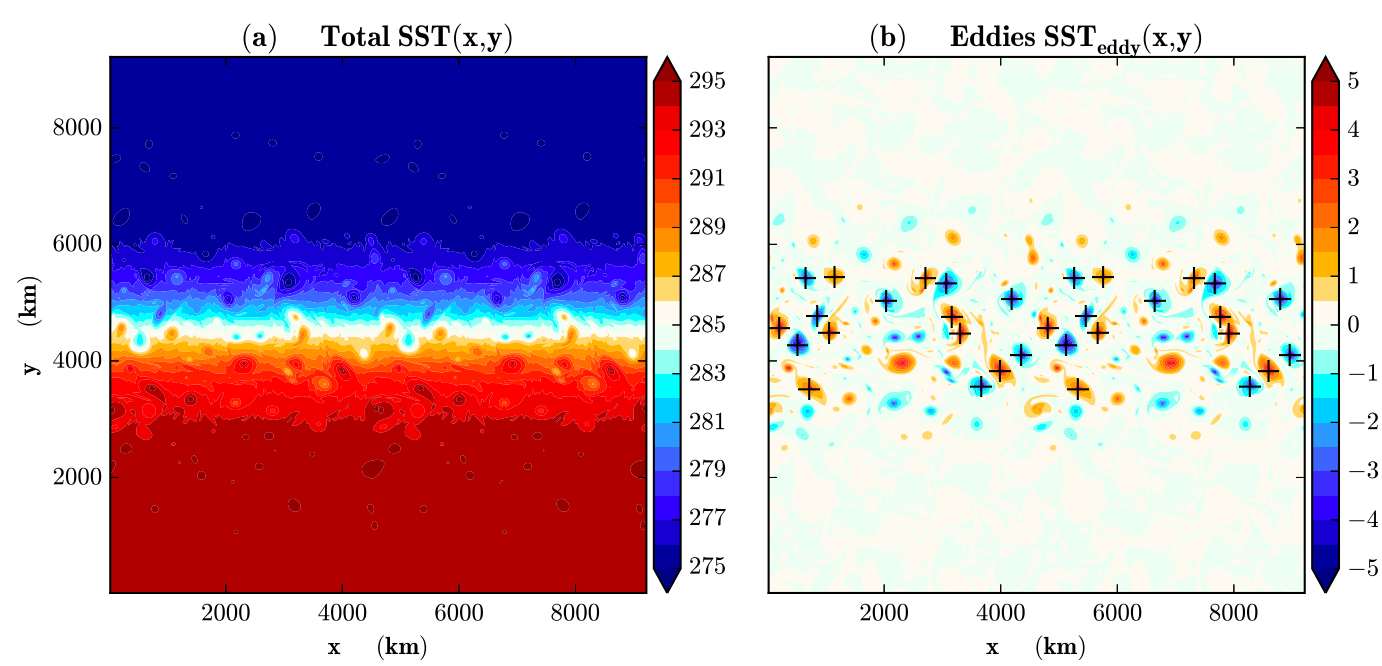

FIG. 1. (a) Total SST and (b) eddy SST fields (K). In (b), black crosses mark centers of the eddies used to create composites following the method described in section 3 .

show the usual response with accelerated (compared to the environment) winds over warm SST anomalies and decelerated winds over cold SST anomalies (Fig. 3). Note that the asymmetry between warm and cold eddies in terms of wind acceleration or deceleration cannot be interpreted since too few eddies served to create the composite fields.

We now turn to the analysis of surface wind divergence. Rather than computing the mean divergence, we choose to separate the response depending on the largescale wind speed. To that end, we have selected conditions with large-scale winds larger than $10 \mathrm{~m} \mathrm{~s}^{-1}$ (to be called strong-wind conditions) and smaller than $3 \mathrm{~m} \mathrm{~s}^{-1}$ (to be called weak-wind conditions). These categories correspond to $33 \%$ and $7 \%$ of instantaneous snapshots, respectively. In the following, we only consider the response to warm eddies as the results with cold eddies are qualitatively similar, but with an opposite sign (not shown). Finally, we have tested that changing the thresholds does not change qualitatively the results.

The divergence of the surface wind reveals significant differences between strong- and weak-wind conditions (Figs. 4a and 4d). Strong-wind conditions (Fig. 4a) are characterized by a dipolar spatial pattern with a divergent wind field upwind of the eddy and a convergent wind field downwind, with a typical amplitude on the order of $10^{-5} \mathrm{~s}^{-1}$. This is consistent with accelerated wind speeds over warm eddies and is similar to observations (e.g., Park et al. 2006; Ma et al. 2015). Note also that the downwind convergence is twice as large as the upwind divergence, which is generally not observed when doing averages over all weather conditions (e.g., Frenger et al. 2013). For weak-wind conditions (Fig. 4d), the situation is different as a strong monopolar convergence pattern is located slightly downwind of the warm eddy.

To determine the importance of the DMM and EBMA, the surface divergence was compared with the downwind SST gradient and the Laplacian of atmospheric temperature in the boundary layer. The downwind $\operatorname{SST}$ gradient $\mathbf{k} \cdot \nabla \operatorname{SST}(x, y, t)=\left[\mathbf{U}_{10 \mathrm{~m}}(x, y, t) /\right.$ $\left.\left|\mathbf{U}_{10 \mathrm{~m}}(x, y, t)\right|\right] \cdot \operatorname{\nabla SST}(x, y)$ was computed for each time output and grid point, then put in the new reference frame. Figures $4 \mathrm{~b}$ and $4 \mathrm{e}$ show this quantity, for strong and weak winds in the case of warm eddies. Because of our specific definition, the downwind SST gradient is different in amplitude for strong- and weak-wind

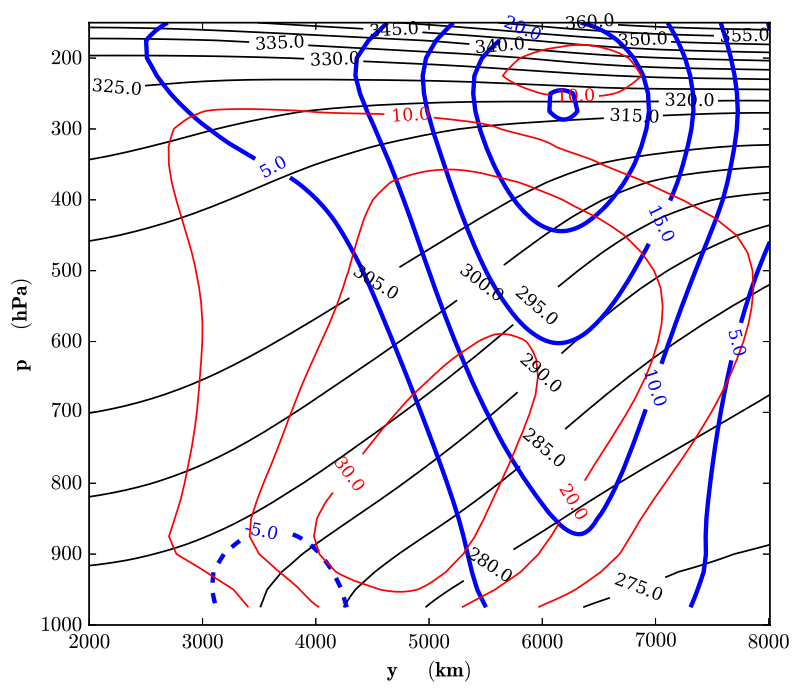

FIG. 2. Time and zonal average of zonal wind (blue thick contours, $\mathrm{m} \mathrm{s}^{-1}$ ), potential temperature (black contours, $\mathrm{K}$ ), and meridional flux of potential temperature (red thick contours, $\mathrm{K} \mathrm{m} \mathrm{s}^{-1}$ ). 
Warm eddy

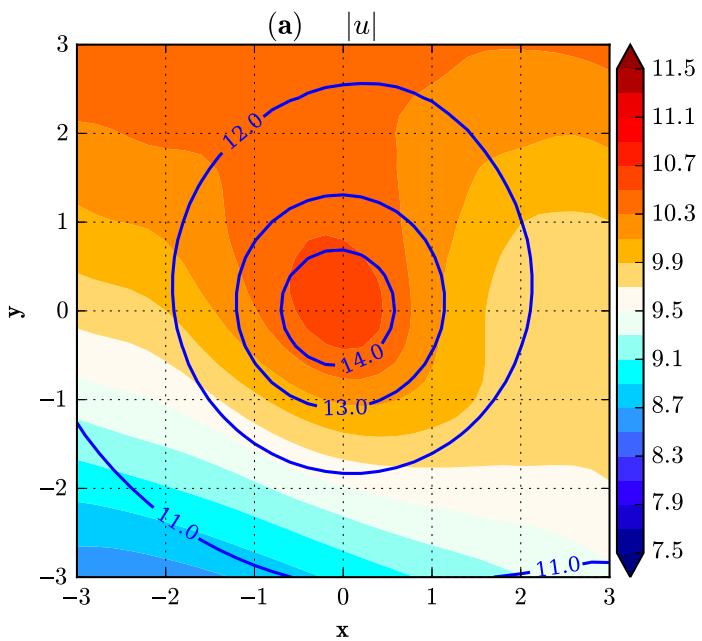

Cold eddy

(b) $|u|$

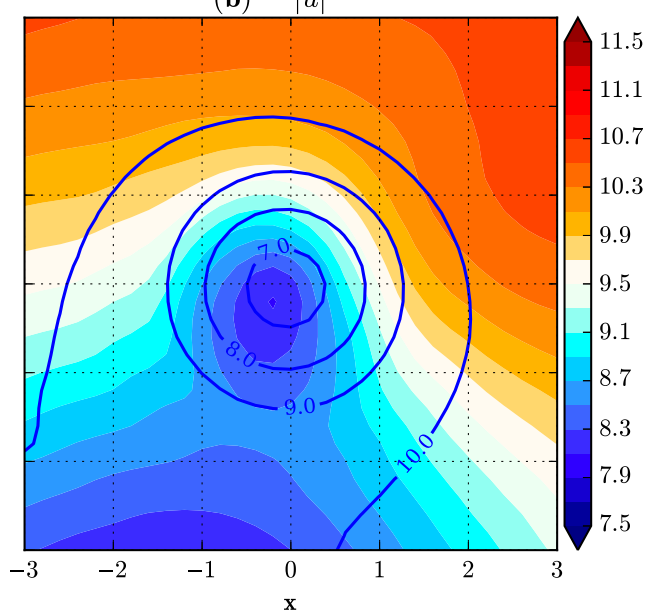

FIG. 3. Composites of surface wind speed $\left\langle\left|\mathbf{U}_{10 \mathrm{~m}}\right|\right\rangle$ (shading, $\mathrm{m} \mathrm{s}^{-1}$ ) and sea surface temperature $\langle\mathrm{SST}\rangle$ (contours, K) for (a) warm and (b) cold eddies.

conditions (Figs. 4b and 4e) but, in both cases, we recover the standard dipolar pattern. For strong-wind conditions, the shape of the downwind SST gradient is similar in part to the shape of the surface divergence (cf. Figs. 4a and 4b), except for the surface convergence zone that extends farther downstream (Fig. 4a). Another difference is that the downwind SST gradient has positive and negative poles with almost equal amplitude
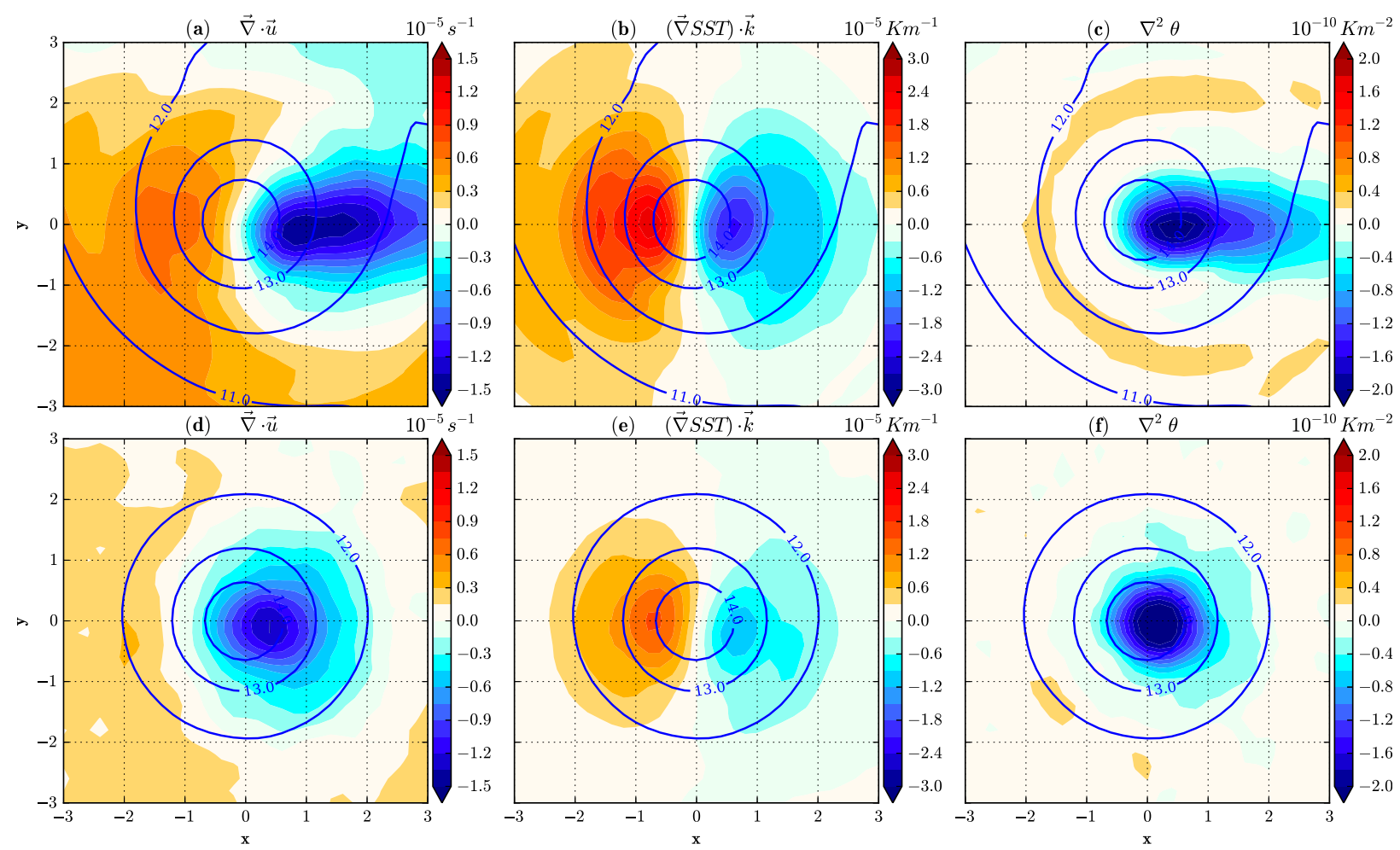

FIG. 4. Composites above warm eddies of (a),(d) divergence of surface wind, (b),(e) downwind SST gradient, and (c),(f) Laplacian of boundary layer temperature under (a)-(c) strong-wind conditions (wind speeds greater than $10 \mathrm{~m} \mathrm{~s}^{-1}$ ) and (d)-(f) weak-wind conditions (wind speeds less than $3 \mathrm{~m} \mathrm{~s}^{-1}$ ). Contours correspond to SST (K). 
contrary to surface divergence for which some asymmetry is apparent. In weak-wind conditions, the downwind SST gradient differs from surface convergence with a monopolar shape for the latter and a dipolar shape for the former (cf. Figs. 4d and 4e).

For each wind condition, the Laplacian of boundary layer temperature $\nabla^{2} \theta$ was computed as the Laplacian of the temperature averaged between the surface and $500 \mathrm{~m}$. It is represented in Figs. $4 \mathrm{c}$ and $4 \mathrm{f}$ for strong and weak winds. For strong winds, it is intensified and negative in the downwind side of the SST anomaly and is located close to the region of largest surface convergence (cf. Figs. 4a and 4c). It thus seems that both the temperature Laplacian and the downwind SST gradient contribute in shaping the surface divergence pattern. This suggests that both DMM and EBMA may be important in setting the spatial variation of the surface divergence field. This result contrasts with the literature (e.g., Kilpatrick et al. 2016) as, in general, the downwind SST gradient seems the dominant parameter especially at high winds. A notable difference with these studies is that they only consider simplified configurations with quasi-unidirectional fronts, so that the temperature Laplacian only comes from either the along- or the crosswind direction. On the contrary, because of the geometry of oceanic eddies, the Laplacian can have variations in both directions. Indeed, in our simulation, it is found that about two-thirds of the pressure Laplacian correspond to crosswind variations of pressure (not shown). Finally, in comparison to the temperature Laplacian, the SST Laplacian is centered over the oceanic eddy and is out of phase with the surface divergence (not shown). This is easily explained as the temperature anomaly that is generated above the warm oceanic eddy is advected downwind, so that SST and atmospheric temperature Laplacian do not correlate.

For weak-wind conditions, the temperature Laplacian is monopolar and negative above the SST anomaly because of weak temperature advection by the wind (Fig. 4f). Comparing Figs. 4d-f, we see that the surface divergence pattern is highly correlated with the temperature Laplacian, while it is not the case when compared to the downwind SST gradient. Actually, because of the weak temperature advection, the SST Laplacian is correlated with the temperature Laplacian as well as with the surface divergence (not shown). This is in agreement with the results of Lambaerts et al. (2013), who examined the fast adjustment of the boundary layer from rest to a turbulent eddy SST field. A possible interpretation of this result can rely on the EBMA mechanism: the warm SST anomaly creates a warm temperature anomaly in the boundary layer, which then creates a convergence field in the Ekman layer.
A last remark concerns moderate-wind conditions (i.e., winds between 3 and $10 \mathrm{~m} \mathrm{~s}^{-1}$ ). In such conditions, it was found that the wind divergence response is between those for the two other wind conditions (not shown).

The difference in terms of the atmospheric response between weak- and strong-wind conditions is reminiscent of results obtained by Chen et al. (2017) for eddies in the Kuroshio Extension region. In their study, they separated two different classes, one with a dipolar pattern in divergence of surface wind (corresponding to $60 \%$ of the oceanic eddies that were observed) and one with a monopolar pattern (corresponding to $10 \%$ of the eddies). The first class was attributed to DMM while the second class to EBMA. An inspection of their Fig. 3c shows that, for the first class of eddies, the convergence maximum extends farther downstream, a result consistent with our result for strong-wind conditions (Fig. 4a).

\section{Atmospheric response to a turbulent field of mesoscale eddies}

The previous section has characterized the response of the wind field at the oceanic eddy scale in a simulation forced by the ocean. It showed that our simulation with fixed SST compares well with observations for strongwind conditions. We now turn to examine the spatial organization of the atmospheric response in relation with the oceanic turbulent field, that is, for scales smaller than $400 \mathrm{~km}$. This contrasts with studies focusing on eddy composites or unidimensional fronts. To this end, we focus on a part of the spatial domain, of width $1400 \mathrm{~km} \times$ $1400 \mathrm{~km}$ and centered at $\left(x_{0}, y_{0}\right)=(5400,4500) \mathrm{km}$, that is, close to the center of the SST front. Results that are discussed hereafter apply for other spatial regions as well within the band where oceanic eddies are present.

In the following, we consider anomalies from the large-scale environment. These turbulent-scale anomalies, denoted as $(\cdot)^{\star}$, are obtained (except for SST) by removing a large-scale component obtained by convoluting with a Gaussian kernel of radius $r_{\text {filter }}=200 \mathrm{~km}$. The SST anomaly SST $_{\text {eddy }}$ is given directly from the boundary condition through (1).

The anomaly of time-mean surface wind speed $\langle|\mathbf{U}|\rangle^{\star}$ is presented in Fig. 5a. Here, $\langle\cdot\rangle$ is the time average for the whole analysis period. It bears striking similarities with $\mathrm{SST}_{\text {eddy }}$ with a correlation coefficient of $r=0.98$ and a regression coefficient of $0.29 \mathrm{~m} \mathrm{~s}^{-1} \mathrm{~K}^{-1}$. This is true for the anomalies associated with oceanic eddies, confirming results of the last section, but also for the filamentary structures in between. The regression coefficient (also called coupling coefficient) is in the range 

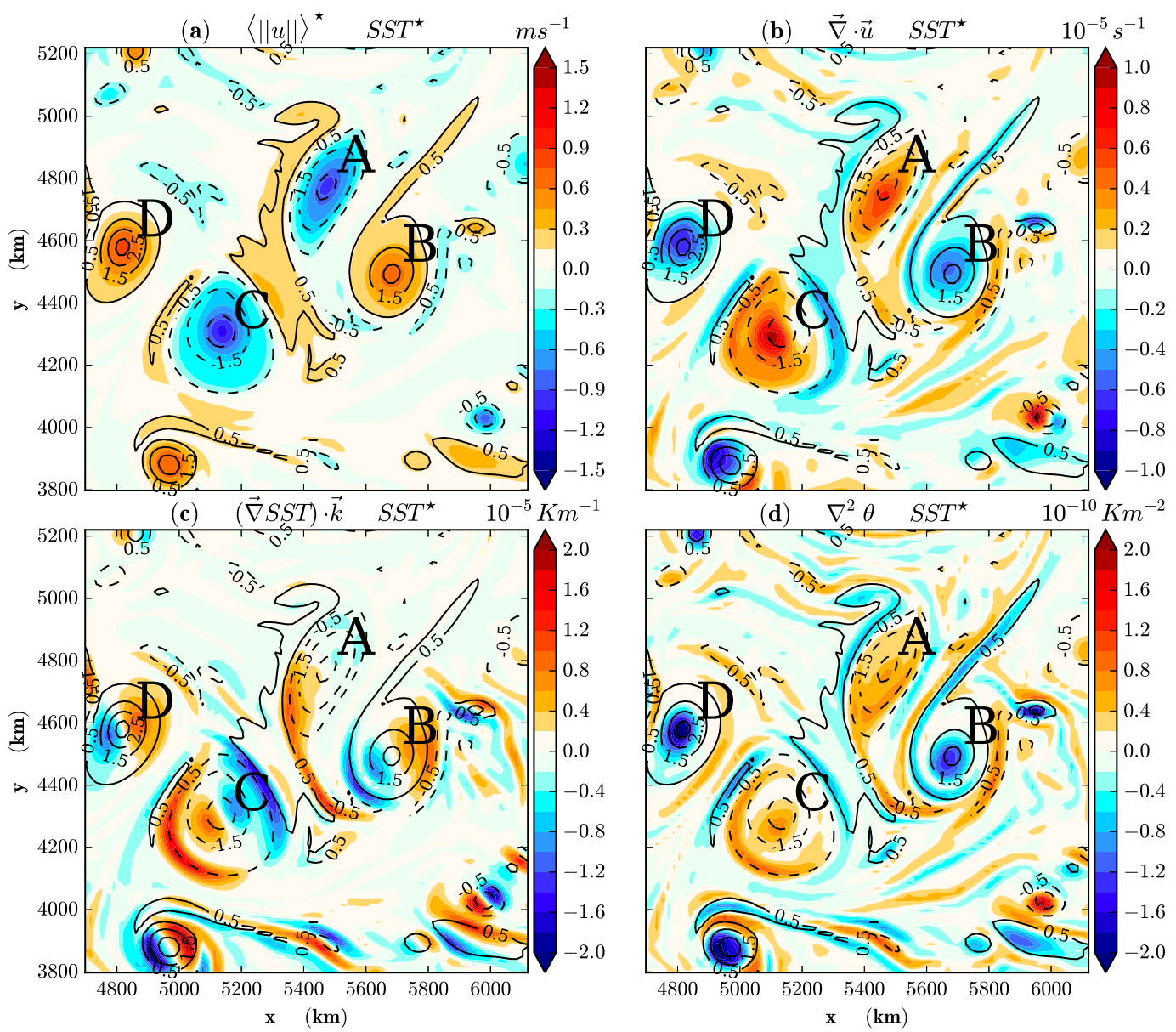

FIG. 5. Anomaly of (a) time-mean surface wind speed $\left\langle\left|\mathbf{U}_{10 \mathrm{~m}}\right|\right\rangle^{\star}\left(\mathrm{m} \mathrm{s}^{-1}\right)$, (b) surface divergence $\left(10^{-5} \mathrm{~s}^{-1}\right)$, (c) downwind SST gradient $\left(10^{-5} \mathrm{~K} \mathrm{~m}^{-1}\right)$, and (d) Laplacian of atmospheric temperature $\left(10^{-10} \mathrm{~K} \mathrm{~m}^{-2}\right)$. Contours are $\mathrm{SST}_{\text {eddy }}(\mathrm{K})$. Letters used to describe particular eddies in this figure are at the same spatial coordinates as those on Figs. 6, 9, and 10.

of the usual values derived from observations (e.g., O'Neill et al. 2012) or from models (Song et al. 2009; Perlin et al. 2014).

The time-mean response in the surface winds generally reflects convergence above warm eddies (such as eddies B or D in Fig. 5b) and divergence above cold eddies (eddies $\mathrm{A}$ or $\mathrm{C}$ ). The divergence field does not bear resemblance with the downwind SST gradients (Fig. 5c) while there is a high correlation with the Laplacian of temperature in the boundary layer (cf. shading in Figs. 5b and 5d). As discussed in the previous section, such a comparison is not helpful to reveal in which wind conditions EBMA or DMM are important. This is probably due to the fact that, in this region, the time-mean wind is weak (not shown).

We propose below to contrast conditions of strong and weak winds as well as different wind directions to better assess the role of the background wind and of the stability of the boundary layer. Several effects are anticipated: The wind speed will influence both how turbulent the boundary layer is and how much advection decorrelates boundary layer temperature from SST. The direction of the wind will also play a role through the presence of the large-scale meridional SST gradient. For example, northerly winds will advect cold air above warm waters, inducing a larger temperature difference between ocean and atmosphere, and hence a more turbulent boundary layer.

\section{a. Method}

Composite atmospheric fields depending on largescale wind conditions are built through the following steps. We consider the square box of size $900 \mathrm{~km} \times$ $900 \mathrm{~km}$, centered at $\left(x_{0}, y_{0}\right)$ and located inside the previously used $1400 \mathrm{~km} \times 1400 \mathrm{~km}$ domain. The chosen box is large enough to be free of local wind variations induced by the SST anomalies, but not too large in order to cover separate synoptic weather patterns. To increase the sampling, we also used the box centered at 
$\left(x_{0}^{\prime}, y_{0}^{\prime}\right)=(1208,4500) \mathrm{km}$ since the SST eddy field was duplicated in longitude. We introduce the wind conditions as the couples $\mathbf{U}_{\mathrm{ls}}=\left(U_{\mathrm{ls}}, V_{\mathrm{ls}}\right)$ for $U_{\mathrm{ls}}=-10,-5,0$, $5,10 \mathrm{~m} \mathrm{~s}^{-1}$ and $V_{\mathrm{ls}}=-10,-5,0,5,10 \mathrm{~m} \mathrm{~s}^{-1}$ ("ls" for large scale). Then, for each 12-h output, the instantaneous wind at $10 \mathrm{~m}$, denoted $\mathbf{U}_{10 \mathrm{~m}}$, is averaged over the $(900 \mathrm{~km} \times$ $900 \mathrm{~km})$ box and is sorted out according to which wind conditions $\left(U_{\mathrm{ls}}, V_{\mathrm{ls}}\right)$ it belongs (within $\pm 2.5 \mathrm{~m} \mathrm{~s}^{-1}$ ). Composite fields $[\cdot]$ are finally constructed by averaging over all outputs belonging to each large-scale wind condition $\left(U_{\mathrm{ls}}, V_{\mathrm{ls}}\right)$. In the following, we will consider composites for which more than 100 time outputs have been averaged. Finally, we introduce $\mathbf{k}=\left[\mathbf{U}_{10 \mathrm{~m}}(x, y, t)\right] /$ $\left[\left|\mathbf{U}_{10 \mathrm{~m}}(x, y, t)\right|\right]$ as a composite vector in the wind direction and $\theta$ the average temperature from the surface to 500-m height.

\section{b. Surface wind divergence}

We now examine the differences of spatial structures in surface wind divergence for different wind conditions. Three large-scale wind conditions are considered in details: northerly strong winds $\left[\mathbf{U}_{\mathrm{ls}}=(0,-10) \mathrm{m} \mathrm{s}^{-1}\right]$, weak winds $\left[\mathbf{U}_{\mathrm{ls}}=(0,0) \mathrm{m} \mathrm{s}^{-1}\right]$, and southerly strong winds $\left[\mathbf{U}_{\mathrm{ls}}=(0,10) \mathrm{m} \mathrm{s}^{-1}\right]$.

Figures $6 \mathrm{a}$ and $6 \mathrm{~b}$ present the surface divergence anomaly $\left[\nabla \cdot \mathbf{U}_{10 \mathrm{~m}}\right]^{\star}$ (in colors) as well as $\mathbf{k} \cdot \nabla \mathrm{SST}_{\text {eddy }}$ and $\left[\nabla^{2} \theta\right]^{\star}$ (in contours), for northerly wind conditions [i.e., $\left.\mathbf{U}_{\mathrm{ls}}=(0,-10) \mathrm{m} \mathrm{s}^{-1}\right]$. At first glance, both $\left[\nabla^{2} \theta\right]^{\star}$ and $\mathbf{k} \cdot \nabla \mathrm{SST}_{\text {eddy }}$ seem to correlate well with the surface wind divergence (correlation coefficients of $r=0.81$ and 0.63 , respectively; see Table 2). However inspecting with more attention Figs. $6 \mathrm{a}$ and $6 \mathrm{~b}$, we note that, at some particular locations, the spatial structures of the downwind SST gradient and the temperature Laplacian are quite different. First, narrow SST structures oriented parallel to the background wind such as the one to the southwest of eddy A produce patterns of wind convergence $\left(\left[\nabla \cdot \mathbf{U}_{10 \mathrm{~m}}\right]^{\star}<0\right)$ while $\mathbf{k} \cdot \nabla \mathrm{SST}_{\text {eddy }}$ is almost zero (Fig. 6a). At this location, surface wind convergence is collocated with negative values of SST Laplacian (not shown) and with negative values of $\left[\nabla^{2} \theta\right]^{\star}$ (see Fig. 6b). Also, for the small warm eddy $\mathrm{D}$, only a monopolar pattern of convergence of surface winds is seen, which differs from the dipolar pattern of $\mathbf{k} \cdot \nabla \mathrm{SST}_{\text {eddy }}$ (Fig. 6a). In fact, at this location, the convergence region is associated with large values of temperature Laplacian $\left[\nabla^{2} \theta\right]^{\star}$ (Fig. 6b). The significant correlation $(r=0.81)$ between surface wind divergence and temperature Laplacian and the similarity of spatial structures suggest that, for strong northerly winds, the surface wind divergence response is mostly due to EBMA. However, because of temperature advection by the northerly wind, correlation of surface divergence with the SST
Laplacian itself remains low, with a correlation coefficient of 0.18 .

The weak-wind case is represented in Figs. $6 \mathrm{c}$ and $6 \mathrm{~d}$. The surface divergence is found to be generally weaker than for northerly winds (cf. Figs. 6a and 6c). Looking at Fig. 6d, surface divergence and temperature Laplacian are well correlated (with a correlation coefficient of $0.63)$. Also, there is a fair correspondence between SST Laplacian and surface divergence (correlation coefficient of 0.39), because the temperature anomalies lie almost above the SST anomalies (not shown). At particular locations (near eddy A, or in some filamentary structures in the northern part of the domain), the surface divergence resembles the downwind SST gradient (Fig. 6c). However, in many other places (such as eddies B, C, D), the two fields do not coincide with each other. We conclude that, in these weak-wind conditions, there is a preferential response following EBMA.

The situation is different for a southerly wind (Figs. 6e and 6f) for which we see a clear correlation of the surface divergence with the downwind SST gradient (correlation coefficient of 0.83 ; see Table 2). This manifests in similar spatial structures not only for eddies B, C, and D but also for several filamentary structures between them. The response above eddies $\mathrm{B}$ and $\mathrm{C}$ shows a typical dipolar structure of convergence-divergence corresponding to a DMM response. On the contrary, the connection between the surface divergence and the temperature Laplacian is less obvious when comparing the spatial structures of the two fields (Fig. 6f), although the spatial correlation is still high (around 0.48).

We now explore more quantitatively and systematically the atmospheric response by computing the correlation coefficients of surface divergence with either the downwind SST gradient (Fig. 7a) or the temperature Laplacian (Fig. 7b) as a function of the wind conditions $\left(U_{\mathrm{ls}}, V_{\mathrm{ls}}\right)$. Two regimes can be distinguished. The first one, for strong southerly $\left(V_{\mathrm{ls}}>0\right)$ or zonal winds, corresponds to a better correlation of the surface divergence with the downwind SST gradient than with the temperature Laplacian. On the contrary, for northerly $\left(V_{\mathrm{ls}}<0\right)$ or for weak winds, the surface divergence better correlates with the temperature Laplacian. Still, there is some correlation with the downwind SST gradient. This last result can be understood by the correlation that is found between $\mathbf{k} \cdot \nabla \mathrm{SST}_{\text {eddy }}$ and $\left[\nabla^{2} \theta\right]^{\star}$, as shown in Fig. 7c. A simple explanation of this correlation comes from the heat budget, which can be approximated by

$$
\mathbf{U}_{\mathrm{ls}} \cdot \nabla[\theta]^{\star} \approx \gamma\left(\mathrm{SST}_{\mathrm{eddy}}-[\theta]^{\star}\right)
$$

where the air-sea heat flux was replaced by a simple relaxation toward SST with a typical time-scale $\gamma^{-1}$. If 
Northerly Wind $(10 \mathrm{~m} / \mathrm{s})$
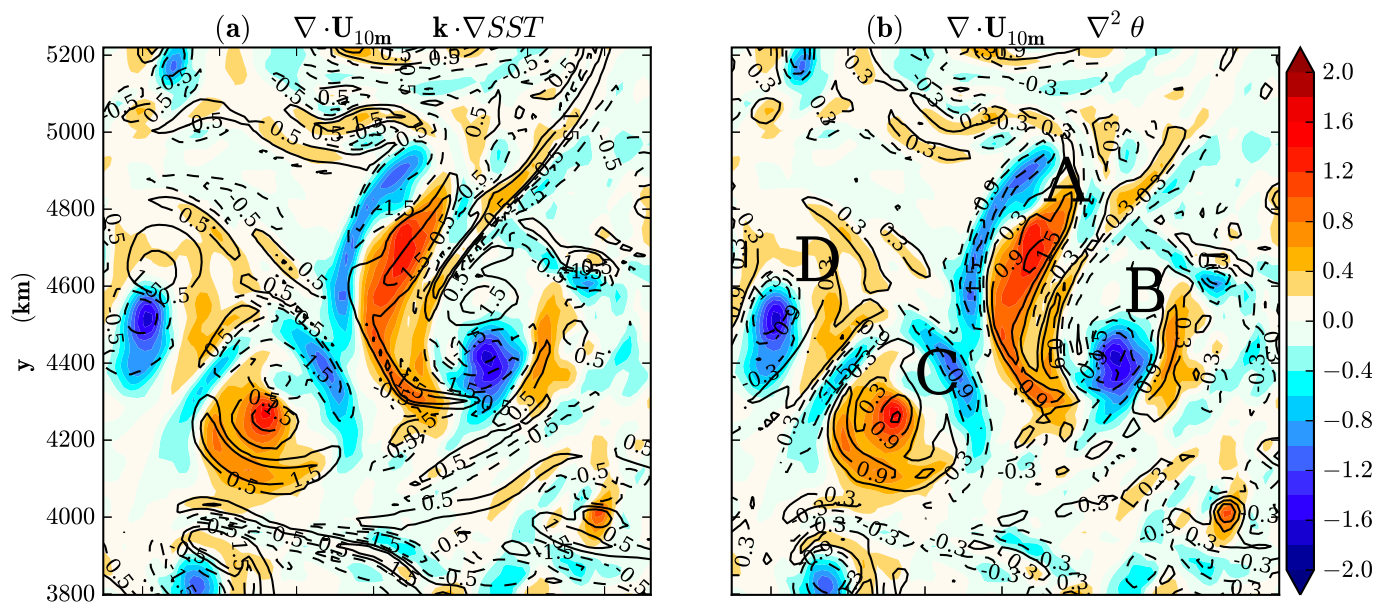

Weak Wind
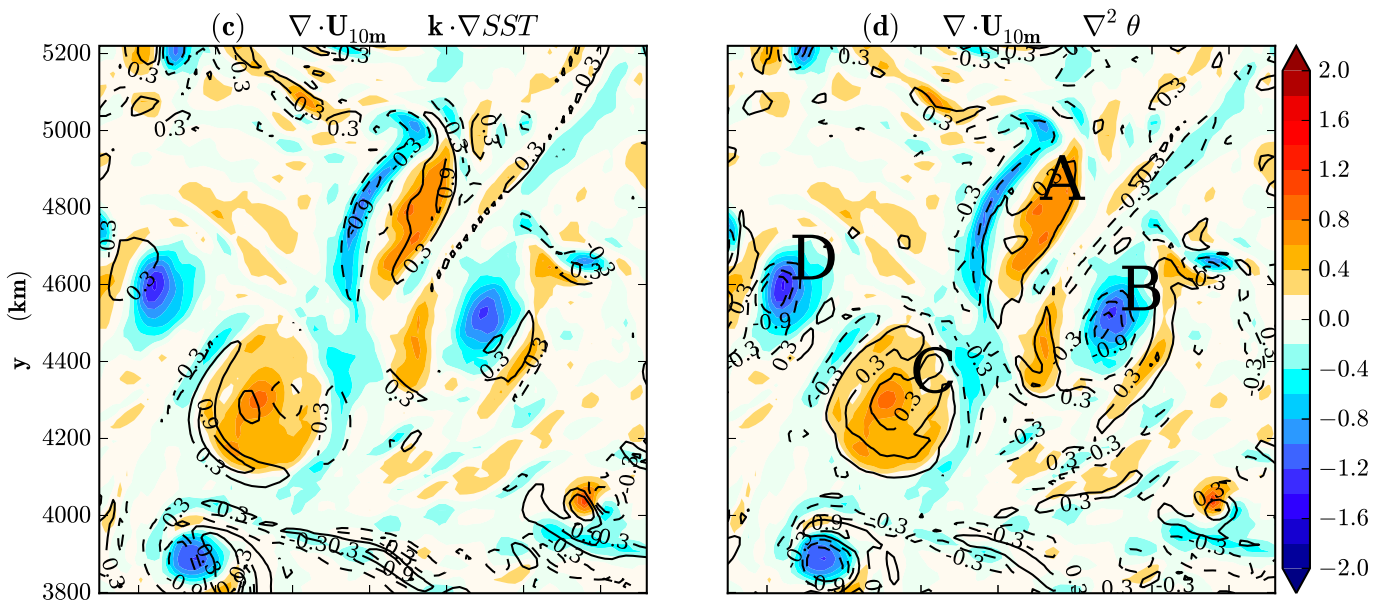

Southerly Wind $(10 \mathrm{~m} / \mathrm{s})$
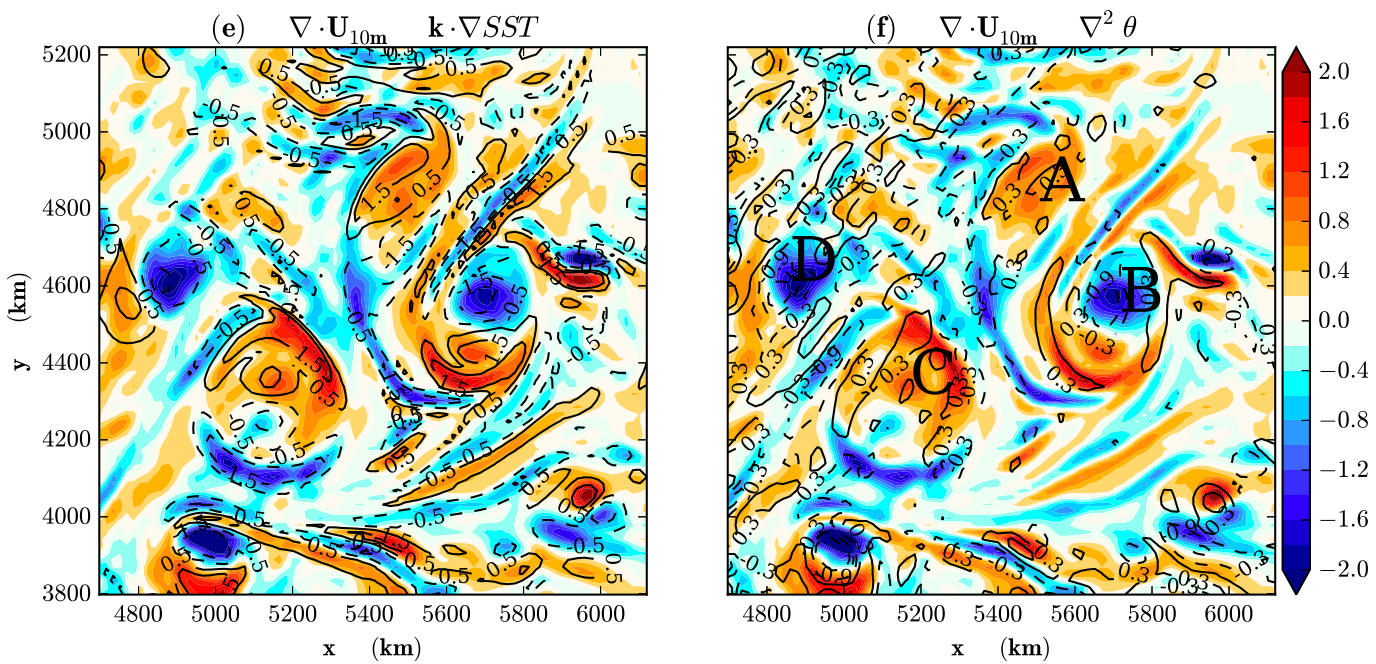

FIG. 6. Composites of surface divergence (shading, $10^{-5} \mathrm{~s}^{-1}$ ) for days with (a),(b) northerly winds, (c),(d) weak winds, and (e),(f) southerly winds. In (a), (c), and (e), contours correspond to the downwind SST gradient $\left(10^{-5} \mathrm{~K} \mathrm{~m}^{-1}\right)$. In (b), (d), and (f), contours correspond to the Laplacian of the atmospheric boundary layer temperature $\left(10^{-10} \mathrm{~K} \mathrm{~m}^{-2}\right)$. 
TABLE 2. Correlation coefficients between different parameters related to wind divergence for northerly, weak, and southerly large-scale winds. Each quantity was computed over the domain displayed in Fig. 5.

\begin{tabular}{lccc}
\hline \hline & \multicolumn{3}{c}{ Weak } \\
& Northerlies & $\begin{array}{c}\text { winds } \\
\text { Southerlies }\end{array}$ \\
\hline$C\left(\left[\nabla \cdot \mathbf{U}_{10 \mathrm{~m}}\right]^{\star},\left[\nabla^{2} \theta\right]^{\star}\right)$ & 0.81 & 0.63 & 0.48 \\
$C\left(\left[\nabla \cdot \mathbf{U}_{10 \mathrm{~m}}\right]^{\star}, \mathbf{k} \cdot \nabla \mathrm{SST}_{\text {eddy }}\right)$ & 0.63 & 0.36 & 0.83 \\
$C\left(\left[\nabla \cdot \mathbf{U}_{10 \mathrm{~m}}\right]^{\star}, \nabla^{2} \mathrm{SST}_{\text {eddies }}\right)$ & 0.18 & 0.39 & 0.08 \\
$C\left(\left[\nabla^{2} \theta\right]^{\star}, \mathbf{k} \cdot \nabla \mathrm{SST}_{\text {eddy }}\right)$ & 0.58 & 0.31 & 0.34 \\
$C\left([w]^{\star},-\left[\nabla^{2} \theta\right]^{\star}\right)$ & 0.76 & 0.73 & 0.43 \\
$C\left([w]^{\star}, \mathbf{k} \cdot \nabla \mathrm{SST}_{\text {eddy }}\right)$ & 0.50 & 0.16 & 0.08 \\
$C\left([w]^{\star},-\nabla^{2} \mathrm{SST}_{\text {eddies }}\right)$ & 0.19 & 0.42 & 0.16 \\
\hline
\end{tabular}

$\mathbf{U}_{\text {ls }}$ points toward $x>0$ with constant modulus, the quantity $\mathbf{U}_{\mathrm{ls}} \cdot \nabla$ can be replaced by $\left|\mathbf{U}_{\mathrm{ls}}\right| \partial / \partial x$. After some algebra, we have

$$
\frac{1}{\gamma}\left|\mathbf{U}_{1 \mathrm{~s}}\right| \frac{\partial^{2}[\theta]^{\star}}{\partial x^{2}}+\mathbf{k} \cdot \nabla[\theta]^{\star}=\mathbf{k} \cdot \nabla \mathrm{SST}_{\text {eddy }} .
$$

For a sufficiently strong wind (i.e., $\left|\mathbf{U}_{\mathrm{ls}}\right| \times\left|\partial_{x} \mathrm{SST}_{\text {eddy }}\right| \gg$ $\left.\gamma\left|\mathrm{SST}_{\text {eddy }}\right|\right)$, the temperature anomaly above the surface heating will be advected downstream and the first term in the lhs of (3) will dominate the second term. In this situation, we obtain a balance between downwind SST gradient and temperature Laplacian, which explains the correlation between the two quantities. This is particularly true for strong winds with a southward component (Fig. 7c and Table 2). Note however that it involves the second derivative only along the wind direction, so that the total Laplacian may not be systematically related to the downwind SST gradient.

To understand why surface divergence correlates with downwind SST gradient in some situations, and with the temperature Laplacian in others, we examine the dependence on the wind conditions of the boundary layer height and the air-sea temperature difference, both spatially averaged over the domain of Fig. 5. The result is displayed in Fig. 8 and is significant in the sense than the mean change of both quantities between different wind conditions is larger than their change across the SST front (for a given wind condition). Northerly winds tend to be associated with high boundary layers (Fig. 8a) and an atmospheric temperature much colder than the underlying SST (Fig. 8b). This can be explained by the advection of cold air from the north, tending to decrease stability over the region that is examined. This results in a typical situation of strong turbulence in the boundary layer associated with a deep boundary layer. Southerly winds are associated with warm air advected in the region creating a stable boundary layer (Fig. 8b), which results in shallow boundary layers (Fig. 8a). These differences can explain the different response in terms of wind divergence, as the surface pressure anomaly and the surface divergence tend to be proportional to the height of the boundary layer (Feliks et al. 2004). Conditions with higher boundary layers will result in stronger EBMA. This can be confirmed by examining the coupling coefficient, computed as the regression coefficient between wind speed anomalies and SST anomalies as a function of the background wind $\left(U_{\mathrm{ls}}, V_{\mathrm{ls}}\right)$. The coupling coefficient is the smallest for northerly winds corresponding to large-scale unstable boundary layers (Fig. 8c). For zonal or southerly winds (corresponding to large-scale stable boundary layers), the coupling coefficient increases with the wind speed, in agreement with Byrne et al. (2015) in their simulation of the Southern Ocean. This confirms that DMM is more efficient for southerlies, resulting in higher correlation
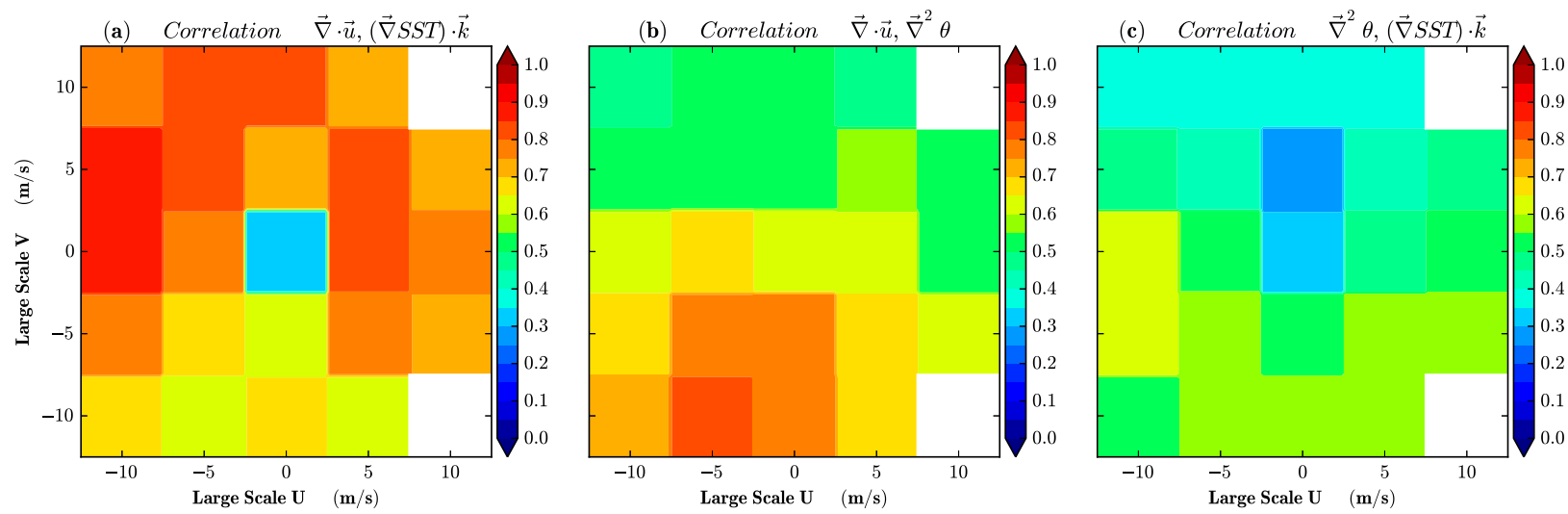

FIG. 7. Correlation coefficient of surface wind divergence with (a) downwind SST gradient and (b) Laplacian of atmospheric boundary layer temperature, as a function of the large-scale background wind at $10 \mathrm{~m}$. (c) Correlation coefficient of downwind SST gradient with Laplacian of temperature. White squares denote an insufficient number of snapshots for averaging over wind conditions. 

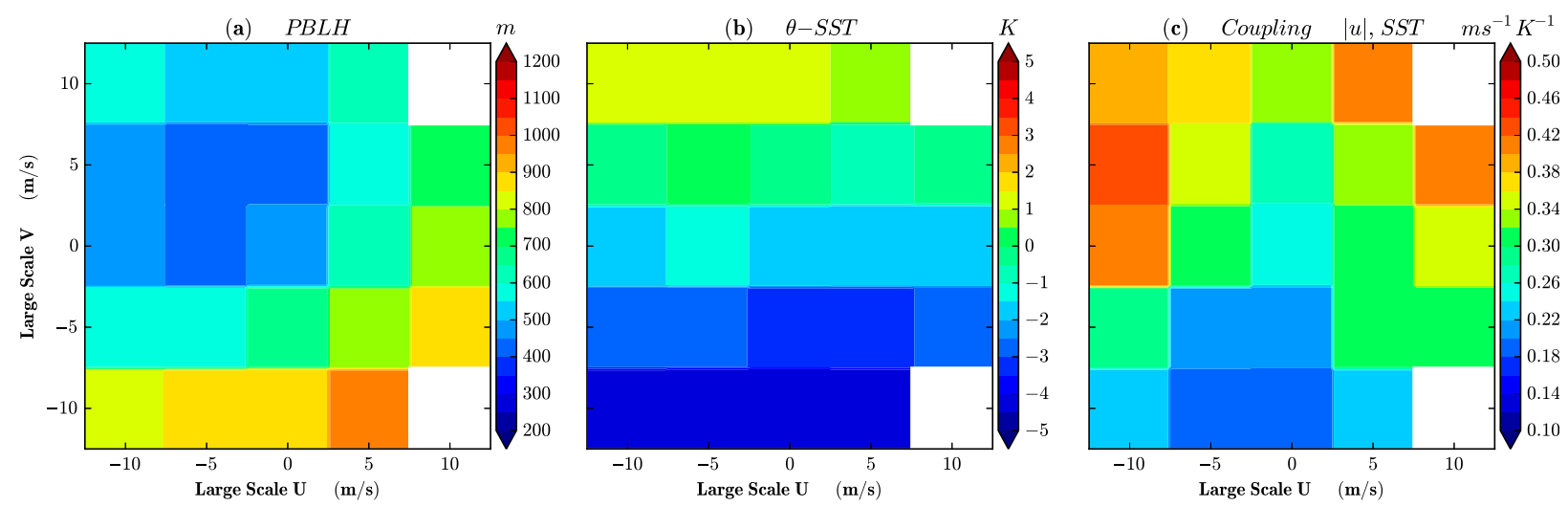

FIG. 8. (a) Boundary layer height (m) and (b) difference between 0 and $500 \mathrm{~m}$ vertically averaged temperature $\theta$ and SST (K). Both quantities are averaged in space and plotted as a function of the large-scale background wind at $10 \mathrm{~m}$. (c) Regression coefficient of wind speed and SST anomalies as a function of the background wind $\left(\mathrm{m} \mathrm{s}^{-1} \mathrm{~K}^{-1}\right)$.

between surface divergence and downwind SST gradient. As suggested by Skyllingstad et al. (2007) and Small et al. (2008), the surface stability, rather than the boundary layer depth, is the more susceptible to explain this behavior.

Note that we repeated the analysis and compared the vertical velocity at $500 \mathrm{~m}\left(w^{\star}\right)$ with downwind SST gradient or temperature Laplacian. For the weakwind conditions (Fig. 9), as well as for the northerly case, the vertical velocity strongly correlates with the temperature Laplacian (with reversed sign) and not with the downwind SST gradient (Table 2). This is true at the scales of the main eddies, as well as at the scales of filaments (not shown). The correlation with the SST Laplacian remains small even in the weakwind case (correlation coefficient of 0.42 compared with 0.73 for the temperature Laplacian). For southerly winds, it is difficult to determine whether vertical velocities are similar to temperature Laplacian or to SST gradients. Instantaneous snapshots are sometimes characterized by a cold front present in the domain, in general oriented south-southwest toward north-northeast. Despite averaging over different snapshots, these fronts leave a residual signature in the vertical velocity field. As a result, the vertical velocity field does not display any organization at the scales of oceanic eddies (not shown).

\section{c. Wind stress divergence}

Several observational studies (O'Neill et al. 2003; Chelton et al. 2004) pointed out a robust relation between wind stress divergence and downwind SST gradient. We now try to relate this result with the response of the surface divergence that we analyzed above.

If we neglect the role of surface oceanic currents, the wind stress vector $\tau$ is written using bulk formula,

$$
\boldsymbol{\tau}=\rho_{0} C_{d}\left|\mathbf{U}_{10 \mathrm{~m}}\right| \mathbf{U}_{10 \mathrm{~m}},
$$

with $C_{d}$ the drag coefficient (Stull 1989). Divergences of surface wind and wind stress are then related by

$$
\nabla \cdot \boldsymbol{\tau}=\rho_{0} \mathbf{U}_{10 \mathrm{~m}} \cdot \nabla\left(C_{d}\left|\mathbf{U}_{10 \mathrm{~m}}\right|\right)+\rho_{0} C_{d}\left|\mathbf{U}_{10 \mathrm{~m}}\right| \nabla \cdot \mathbf{U}_{10 \mathrm{~m}} .
$$

The first term on the rhs of (5) describes the effect of spatial variations of stress-to-wind ratio (i.e., $|\boldsymbol{\tau}| /\left|\mathbf{U}_{10 \mathrm{~m}}\right|=$ $\left.C_{d}\left|\mathbf{U}_{10 \mathrm{~m}}\right|\right)$. Since both $C_{d}$ and $\left|\mathbf{U}_{10 \mathrm{~m}}\right|$ vary with air-sea temperature difference, and hence to some extent with SST, we expect $\mathbf{U}_{10 \mathrm{~m}} \cdot \nabla\left(C_{d}\left|\mathbf{U}_{10 \mathrm{~m}}\right|\right)$ to be proportional to the downwind SST gradient. The second term on the rhs of (5) describes the direct effect of the spatial variation of the wind direction, and more generally the divergence of the wind vector. As seen above, for an

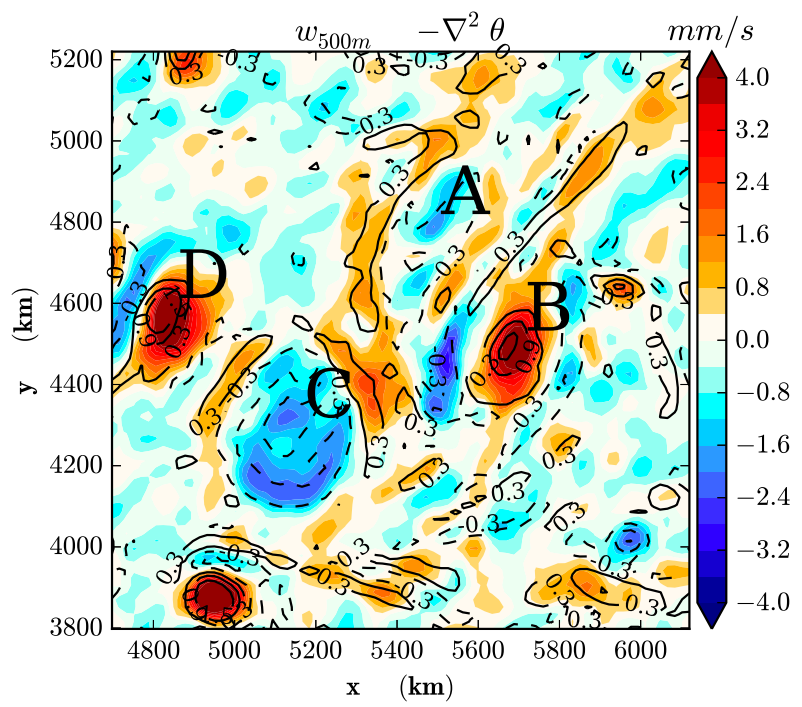

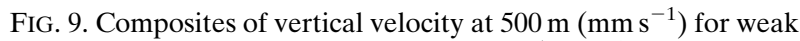
winds. Contours correspond to $-\left[\nabla^{2} \theta\right]^{\star}\left(10^{-10} \mathrm{~K} \mathrm{~m}^{-2}\right)$. 
unstable boundary layer or for weak winds, $\left[\nabla \cdot \mathbf{U}_{10 \mathrm{~m}}\right]^{\star}$ is generally proportional to the temperature Laplacian, and this should also be the case for the last term of (5) as well.

To examine the sensitivity of wind stress divergence to the wind direction, we approximate (5) by

$$
\begin{aligned}
{[\nabla \cdot \tau] \approx } & \underbrace{\rho_{0}\left[\mathbf{U}_{10 \mathrm{~m}}\right] \cdot \nabla\left[C_{d}\left|\mathbf{U}_{10 \mathrm{~m}}\right|\right]}_{E_{\text {stab }}} \\
& +\underbrace{\rho_{0}\left[C_{d}\left|\mathbf{U}_{10 \mathrm{~m}}\right|\right] \cdot \nabla\left[\mathbf{U}_{10 \mathrm{~m}}\right]}_{E_{\text {div }}}
\end{aligned}
$$

with a constant density $\rho_{0}=1.2 \mathrm{~kg} \mathrm{~m}^{-3}$. In the following, we will consider the anomalies from the large-scale environment, for example, $[\nabla \cdot \tau]^{\star}$. Quantities $E_{\text {stab }}$ and $E_{\text {div }}$ will refer to their anomalies. Relation (6) was assessed and revealed to be valid with an RMS error of about $20 \%$ and a good correlation between the wind stress and its approximation (6). The error rises to $38 \%$ for weak winds (because the sum of the two terms underestimates $[\nabla \cdot \tau]$ by $20 \%)$.

Figure 10a presents the divergence of the wind stress for northerly winds $\left[\mathbf{U}_{1 \mathrm{~s}}=(0,-10) \mathrm{m} \mathrm{s}^{-1}\right]$ while Figs. $10 \mathrm{~b}$ and $10 \mathrm{c}$ present its two components following decomposition (6). Comparing Figs. 10b and 10c, term $E_{\text {stab }}$ is in general larger than term $E_{\text {div }}$ (RMS ratio of 1.69; see Table 4). The role of DMM in shaping the wind stress divergence can be understood by realizing that $E_{\text {stab }}$ is proportional to the downwind gradient of SST with a correlation coefficient of 0.97 (see Table 3). This relation reflects the fact that variations of the drag coefficient $C_{d}$ and the surface wind speed are closely linked to SST variations. Indeed, the correlation coefficient of $[\nabla \cdot \tau]^{\star}$ with $[\mathbf{k}] \cdot \nabla \mathrm{SST}_{\text {eddy }}$ is 0.91 (Table 3), which is in agreement with the role of vertical stability in explaining the spatial patterns of wind stress divergence. Term $E_{\text {div }}$ tends to reinforce the divergence close to the eddy centers (e.g., eddies B and D) and also explains a significant part of $[\nabla \cdot \tau]^{\star}$ above filamentary structures in SST between eddies C and D or to the southwest of eddy $\mathrm{A}$. This is in agreement with a correlation coefficient of 0.73 between wind stress divergence and temperature Laplacian.

For weak-winds conditions $\left[\mathbf{U}_{\mathrm{ls}}=(0,0)\right]$, the wind stress is smaller than for the northerly case (ratio of RMS of 0.38 ); $E_{\text {div }}$ is of comparable magnitude with $E_{\text {stab }}$ (RMS of $0.40 \times 10^{-7}$ against $0.46 \times 10^{-7} \mathrm{~N} \mathrm{~m}^{-3}$ ). As in the previous case, $E_{\text {stab }}$ is found to be correlated with downwind SST gradients (see Fig. 10e) with a correlation coefficient of 0.94 , while $E_{\text {div }}$ correlates with the temperature Laplacian (Fig. 10f) with a correlation coefficient of 0.70 . Both terms significantly contribute to the wind stress spatial pattern: term $E_{\text {div }}$ generally dominates close to eddy centers (e.g., eddies B and D) or far from the eddies (e.g., north of eddies $\mathrm{C}$ and D; Fig. 10f), while $E_{\text {stab }}$ dominates in smaller-scale structures at the eddy peripheries such as near eddies $\mathrm{A}$ and C (Fig. 10e). Weak-wind conditions are therefore prone to a correlation between wind stress divergence and temperature Laplacian, when considering scales around $200 \mathrm{~km}$, while both downwind SST gradient and temperature Laplacian matter for smaller scales.

We now consider the case of southerly winds; that is, $\mathbf{U}_{\mathrm{ls}}=(0,10) \mathrm{m} \mathrm{s}^{-1}$ (Figs. 10g-i). First, the wind stress divergence has an opposite sign with the case of northerly winds (cf. Figs. 10a and $10 \mathrm{~g}$ ). This is related to the high correlation of $[\nabla \cdot \tau]^{\star}$ with $\mathbf{k} \cdot \nabla \mathrm{SST}_{\text {eddy }}$ (correlation coefficient of 0.93 ). Two reasons can be invoked: $E_{\text {stab }}$ is in general $61 \%$ larger than $E_{\text {div }}$ (Table 4); $E_{\text {div }}$ (as well as surface divergence) is better correlated with $\mathbf{k} \cdot \nabla \mathrm{SST}_{\text {eddy }}$ than with $\left[\nabla^{2} \theta\right]^{\star}$.

More generally, for all wind conditions of $\mathbf{U}_{\mathrm{ls}}$ (except for weak winds), the correlation between wind stress divergence and downwind SST gradient is higher than 0.80 (Fig. 11a). The correlation with the temperature Laplacian is smaller (Fig. 11b) but still increases to values around 0.7 for northerly winds. The wind stress divergence response is clearly different from the surface wind divergence, as the correlation with the downwind SST gradient always dominates in the first case (Figs. 11a and 11b), while both downwind SST gradient and temperature Laplacian were important for the second case (Figs. 7a and 7b).

Figure 11c shows the value of the regression coefficient between wind stress divergence and downwind SST gradient for all wind conditions. Values are of the typical range of those found in the literature (Perlin et al. 2014). The first dependence of the regression coefficient is on the wind speed, consistent with observations (e.g., O'Neill et al. 2012). It is modulated by the direction of the large-scale background wind relative to the large-scale front, in agreement with the coupling coefficient between wind speed and SST (Fig. 8c).

We conclude that the response in wind stress divergence to SST anomalies depends both on the magnitude of the mean surface wind and on the stability of the atmospheric boundary layer. In strong-wind conditions, we essentially find a wind stress divergence proportional to the downwind SST gradient. This is true for stable as well as for unstable boundary layers and is in agreement with the results of O'Neill et al. (2003) and Chelton et al. (2004). It can be understood as the addition of two effects in the wind stress. The first one comes from the variation of the drag coefficient and the surface wind speed due to SST [in relation with 

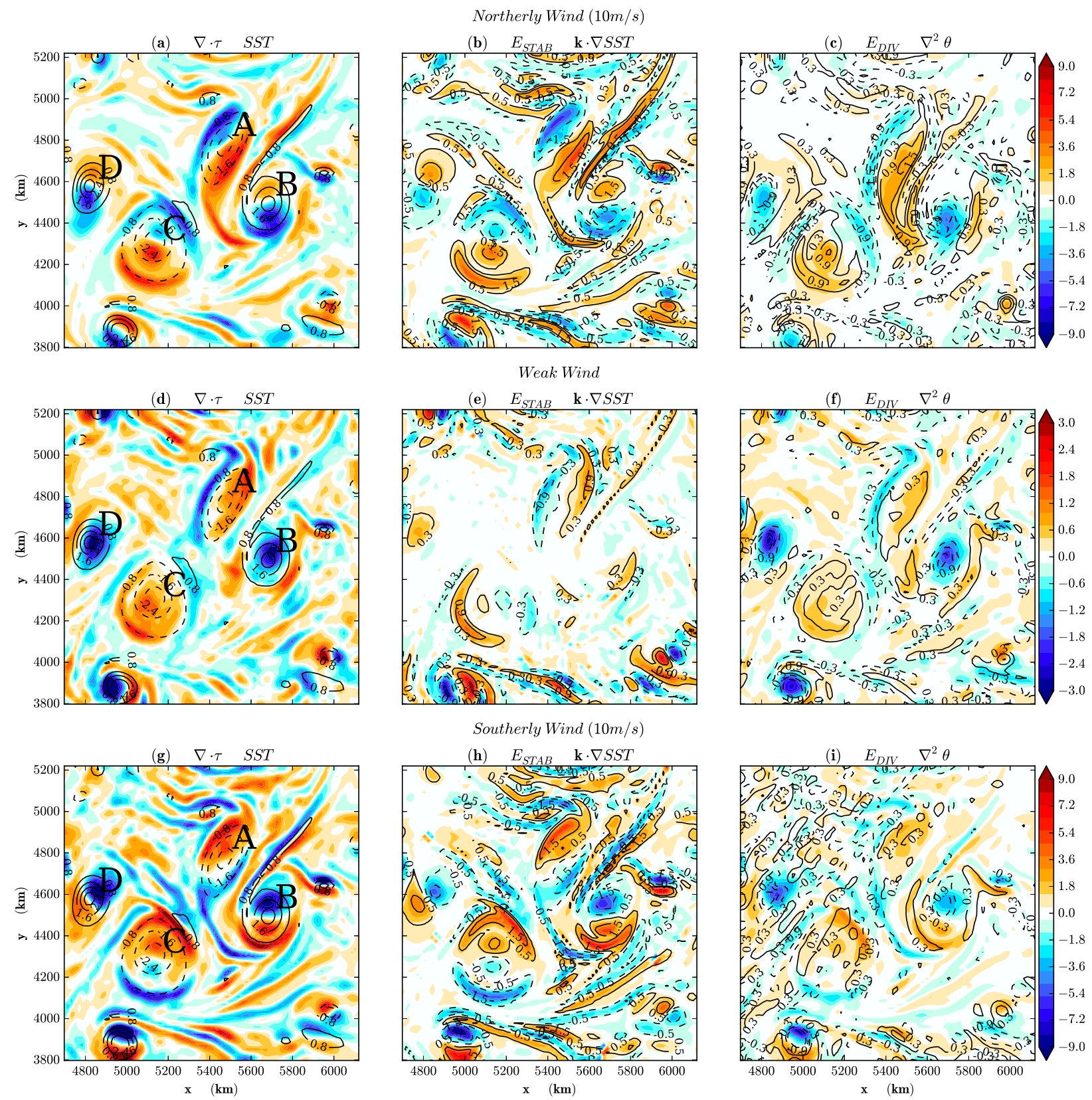

FIG. 10. (a),(d),(g) Composites of wind stress divergence $[\nabla \cdot \tau]^{\star},(\mathrm{b}),(\mathrm{e}),(\mathrm{h})$ stability effect on wind stress divergence $E_{\text {stab}}$, and (c),(f),(i) wind divergence effect on wind stress divergence $E_{\text {div }}$. Units are in $10^{-7} \mathrm{~N} \mathrm{~m}^{-3}$. Contours in (a), (d), and (g) correspond to $\operatorname{SST}_{\text {eddy }}(\mathrm{K})$. Contours in (b), (e), and (h) correspond to $\left[\mathbf{U}_{10 \mathrm{~m}}\right] \cdot \nabla \mathrm{SST}_{\text {eddy }}\left(10^{-5} \mathrm{~K} \mathrm{~m} \mathrm{~s}^{-1}\right)$. Contours in (c), (f), and (i) correspond to $\left[\nabla^{2} \theta\right]^{\star}\left(10^{-10} \mathrm{~K} \mathrm{~m}^{-2}\right)$. (a)-(c) Strong northerly winds, (d)-(f) weak winds, and (g)-(i) strong southerly winds.

$\left.\nabla\left(C_{d}\left|\mathbf{U}_{10 \mathrm{~m}}\right|\right)\right]$ and generally dominates. It is responsible for a response related to the downwind SST gradient. The second effect comes from the direction and intensity of the wind (related to $\nabla \cdot \mathbf{U}_{10 \mathrm{~m}}$ ). Its contribution is large for unstable boundary layers in strongwind conditions. In that case, the two effects add up as they have similar spatial characteristics. For weak winds, the contribution of the second effect becomes as important as the first one, in particular at scales around $200 \mathrm{~km}$.

\section{Conclusions}

In the present study, the response of surface winds to SST anomalies associated with oceanic eddies has been explored in an idealized simulation of an atmospheric 
TABLE 3. Correlation coefficients between different parameters related to wind stress divergence for northerly, weak, and southerly large-scale winds.

\begin{tabular}{lccc}
\hline \hline & Northerlies & Weak winds & Southerlies \\
\hline$C\left([\nabla \cdot \boldsymbol{\tau}]^{\star},\left[\nabla^{2} \theta\right]^{\star}\right)$ & 0.73 & 0.58 & 0.43 \\
$C\left([\nabla \cdot \boldsymbol{\tau}]^{\star}, \mathbf{k} \cdot \nabla \mathrm{SST}_{\text {eddy }}\right)$ & 0.91 & 0.68 & 0.93 \\
$C\left([\nabla \cdot \boldsymbol{\tau}]^{\star}, \nabla^{2} \mathrm{SST}_{\text {eddies }}\right)$ & 0.07 & 0.27 & 0.05 \\
$C\left(E_{\text {stab }}, \mathbf{k} \cdot \nabla \mathrm{SST}_{\text {eddy }}\right)$ & 0.97 & 0.94 & 0.94 \\
$C\left(E_{\text {div }}, \mathbf{k} \cdot \nabla \mathrm{SST}_{\text {eddy }}\right)$ & 0.64 & 0.34 & 0.80 \\
$C\left(E_{\text {div }}, \nabla^{2} \theta^{\star}\right)$ & 0.79 & 0.65 & 0.51 \\
\hline
\end{tabular}

storm track. Two mechanisms are generally invoked to explain the response in terms of divergence of surface wind and wind stress. A first one is related to pressure adjustment (EBMA mechanism; Lindzen and Nigam 1987) while a second is related to downward momentum mixing (DMM mechanism; Wallace et al. 1989). It is expected that the surface wind divergence resembles the Laplacian of the atmospheric temperature in the first case and the downwind SST gradient in the latter case. Our study has documented in which large-scale wind conditions one of the mechanisms is more active than the other. One advantage of our idealized simulation approach is that we could directly inspect the response in surface winds, contrary to other studies that considered equivalent neutral winds or wind stress. Also, using instantaneous winds averaged in composites (grouping together similar large-scale wind conditions) allows us to separate the rapid response without a temporal filter, in a manner similar to Byrne et al. (2015).

We first examined the response at the oceanic eddy scale through a composite analysis. It revealed that the surface wind divergence projects both onto the downwind SST gradient and onto the Laplacian of the atmospheric temperature in the boundary layer. For weak winds, the divergence of surface wind is proportional to the Laplacian of the boundary layer temperature. On the other hand, for strong winds, the surface divergence has a main pattern similar to the downwind SST gradient, but with a downstream extension (related to the temperature Laplacian spatial extension).

The atmospheric response was then investigated over a large region including a field of mesoscale oceanic eddies and filaments of scales between 40 and $400 \mathrm{~km}$. The analysis revealed a more complex response that depends on the wind conditions, and more generally on the mean stability of the boundary layer. For large-scale unstable conditions or for weak winds, the divergence of the surface wind is correlated with the temperature Laplacian (corresponding to EBMA), while for largescale stable conditions, it is correlated with downwind SST gradient (corresponding to DMM). For strong winds, the correlation of the surface divergence with the
TABLE 4. RMS values of different parameters related to wind stress divergence for northerly, weak, and southerly large-scale winds.

\begin{tabular}{lccc}
\hline \hline & \multicolumn{3}{c}{ Weak } \\
& Northerlies & winds & Southerlies \\
\hline $\operatorname{RMS}\left(E_{\text {stab }}\right)\left(10^{-7} \mathrm{~N} \mathrm{~m}^{-3}\right)$ & 1.44 & 0.46 & 1.78 \\
$\operatorname{RMS}\left(E_{\text {div }}\right)\left(10^{-7} \mathrm{~N} \mathrm{~m}^{-3}\right)$ & 0.85 & 0.40 & 1.10 \\
$\operatorname{RMS}\left([\nabla \cdot \tau]^{\star}\right)\left(10^{-7} \mathrm{~N} \mathrm{~m}^{-3}\right)$ & 2.09 & 0.80 & 2.96 \\
\hline
\end{tabular}

SST Laplacian is found to be small, because of the effect of the mean-wind advection.

Concerning the response in terms of wind stress divergence, a different picture is obtained. For strong winds, the divergence of wind stress is proportional to downwind SST gradient, even in large-scale unstable conditions. For weak winds, wind stress divergence is proportional to some extent to the temperature Laplacian. These results are valid at the scales of oceanic eddies, as well as smaller filamentary scales. This discussion shows that wind stress and surface wind divergences may behave differently considering their response to SST anomalies. We point out that such a distinction is rarely made in the literature and should be given greater consideration. Actually wind stress is directly related to the stability of the boundary layer while horizontal velocities in the atmosphere are less so but have a strong dependence on gradients of boundary layer temperature.

Several studies have examined the relevant parameters that set the atmospheric response sensitivity to DMM (Spall 2007; Small et al. 2008; Schneider and Qiu 2015; Ayet and Redelsperger 2019). The first one is related to the magnitude of the mean wind speed. Our study confirms that the relative importance of DMM increases with wind speed. This is shown by a better correlation of surface divergence with downwind SST gradient than with temperature Laplacian for strong winds, except in situations of winds blowing from cold to warm waters. A second important parameter is the spatial scale of the SST field (Small et al. 2008). One would expect the smaller the length scale, the larger the sensitivity to DMM. However, for strong winds blowing from cold to warm waters, we found that EBMA still dominates with surface divergence proportional to temperature Laplacian down to $40 \mathrm{~km}$. The dominance of EBMA over DMM (in terms of relation between surface wind divergence and temperature Laplacian or downwind SST gradient) was found to be related to the large-scale stability of the boundary layer. For unstable and deep boundary layers, an EBMA response is found, while DMM prevails for large-scale stable conditions. This may be related to the dependence of the pressure Laplacian to the mean height of the boundary layer 

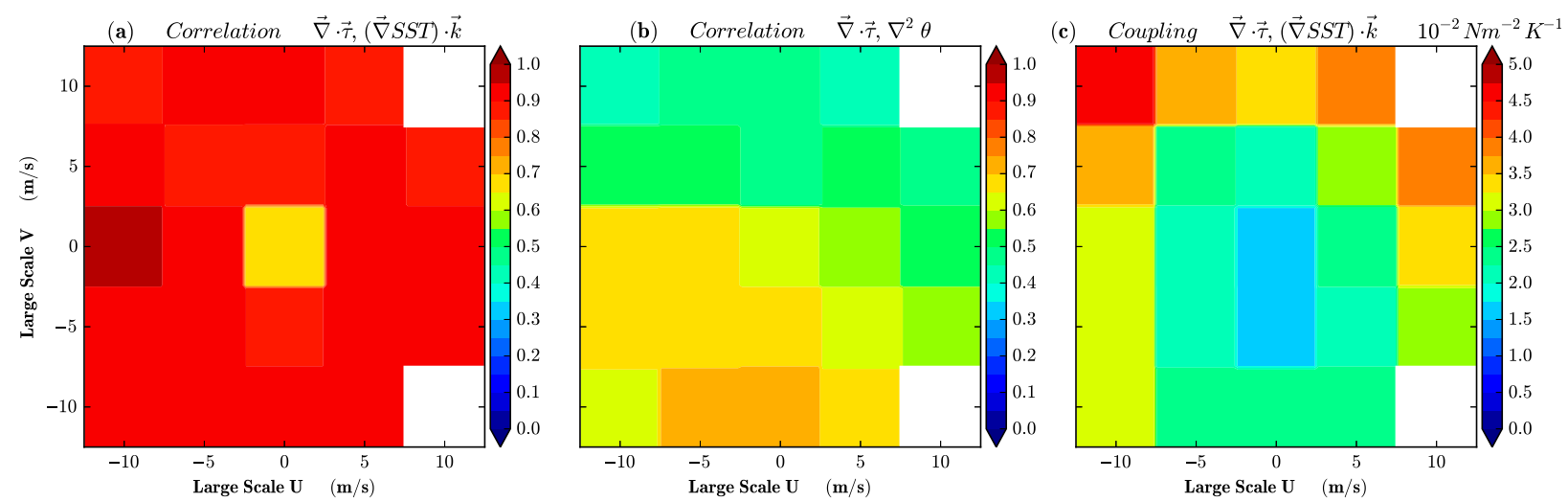

FIG. 11. Correlation coefficient of wind stress divergence with (a) downwind SST gradient and (b) temperature Laplacian. (c) Regression coefficient of wind stress divergence and downwind SST gradient anomalies as a function of the large-scale background wind at $10 \mathrm{~m}\left(10^{-2} \mathrm{~N} \mathrm{~m}^{-2} \mathrm{~K}^{-1}\right)$.

(which favors EBMA) and to the dependence of the coupling coefficient (between wind and SST anomalies) on the stability (which favors DMM).

As the focus of the paper concerns the boundary layer and surface dynamics, we did a sensitivity study to the boundary layer parameterization scheme, using the MellorYamada-Nakanishi-Niino (MYNN) scheme (Nakanishi and Niino 2004). We obtained qualitatively similar results (see Fig. 12), but with different intensities in agreement with results of Lambaerts et al. (2013) and Perlin et al. (2014). A sensitivity to the number of vertical levels within the first $1000 \mathrm{~m}$ showed a weak dependence of the results on vertical resolution as well.

The present study has different limitations. The first one is the stationarity in time of the oceanic anomalies especially for scales below $50 \mathrm{~km}$. However, because of the fast variability of the atmosphere, conditions of given wind do not occur over long time scales compared to the SST variability of the ocean. Therefore, the composite analysis focuses only on the rapid response of the atmosphere and not on its time average, which is tightly linked to fixed SST. Another limitation is the fact that ocean-atmosphere coupling was not considered although different feedbacks are known to modify the surface wind response to oceanic mesoscale anomalies. In particular, our parameterization of the surface atmospheric layer does not take into account ocean currents modulation on the wind work (Renault et al. 2016; Moulin and Wirth 2016; Takatama and Schneider 2017). Moreover the air-sea coupling tend to damp oceanic eddies through Ekman pumping at the scale of oceanic eddies (Stern 1965; Dewar and Flierl 1987) as well at the scale of a turbulent eddy field (Oerder et al. 2018). A full airsea coupling could reduce the SST amplitude and modulate the atmospheric response. These different
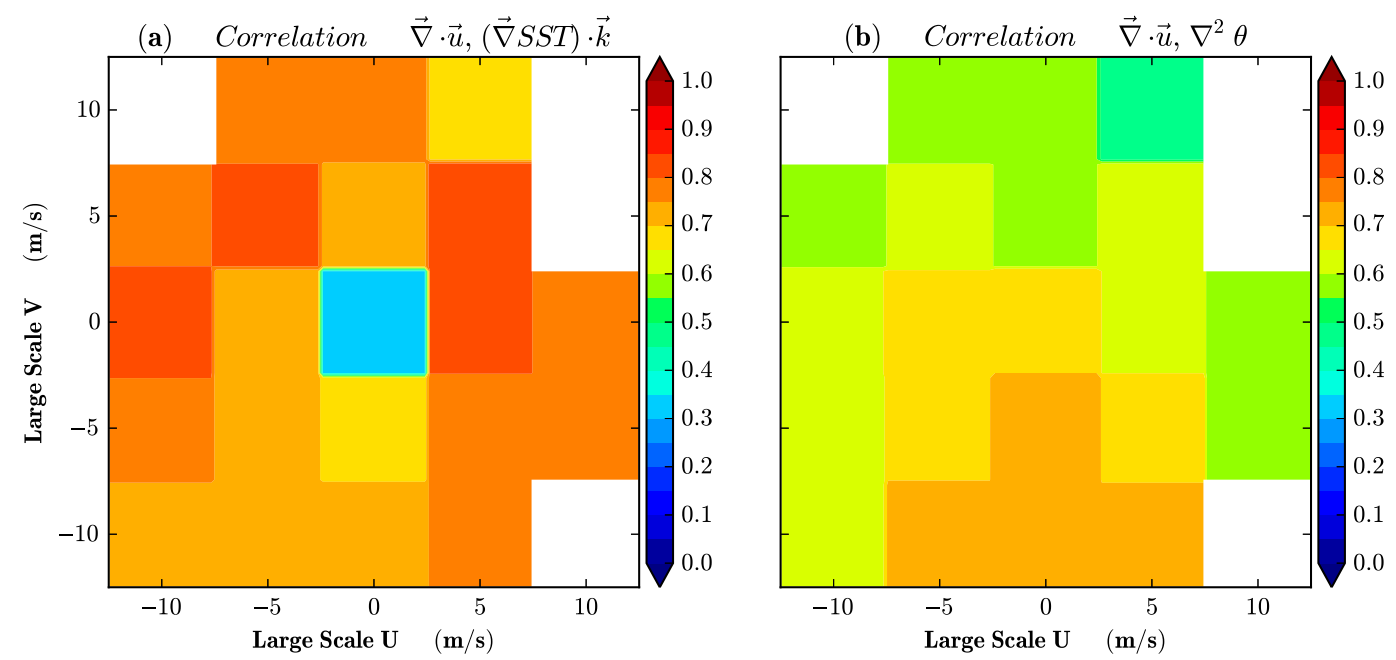

FIG. 12. As in Figs. 7a and 7b, but for the simulation with the MYNN parameterization. 
mechanisms need to be taken into account in future studies.

Acknowledgments. This work was granted access to the HPC resources of IDRIS under the allocation A0020106852 from Grand Equipement National de Calcul Intensif (GENCI). The authors want to thank Arnaud Czaja, Caroline Muller, and Gwendal Rivière for useful discussion about this work and three anonymous reviewers for their time and numerous comments that significantly improved the clarity of the results and discussion.

\section{APPENDIX A}

\section{Coriolis Parameter}

The Coriolis parameter $f$ has the following dependence in $y$ :

$$
f(y)=f_{0}+\beta_{\max } l_{\beta} \tanh \left(\frac{y-y_{\mathrm{sst}}}{l_{\beta}}\right) .
$$

This formula in addition to parameters in Table 1 allows us to model a storm track with a Coriolis parameter that ranges between values at $27.6^{\circ}$ and $55.6^{\circ} \mathrm{N}$. The $\beta$ effect above the oceanic front has a realistic value of $\beta_{\max }=1.75 \times 10^{-11} \mathrm{~m}^{-1} \mathrm{~s}^{-1}$, corresponding to its value at a latitude of $40^{\circ} \mathrm{N}$. In this way, we obtain a strong planetary vorticity gradient, which helps to maintain the eddy-driven jet to its mean position. Using a linear function for $f$ with the same value of $\beta=\beta_{\max }$ would lead to unrealistic values of $f$ on the northern or southern part of the domain.

\section{APPENDIX B \\ Radiative Scheme}

The radiative scheme that is used in our simulation is a gray-radiation scheme following the ideas of Frierson et al. (2006). We introduce $T$ as the absolute temperature and $D$ the optical depth (with the convention $D=0$ at the top of the atmosphere and $D=D_{0}$ at the surface). The equations for upward $\left(F^{\uparrow}\right)$ and downward $\left(F^{\downarrow}\right)$ radiative energy fluxes are

$$
\begin{aligned}
& \frac{d F^{\uparrow}}{d D}=F^{\uparrow}-\sigma T^{4}, \\
& \frac{d F^{\downarrow}}{d D}=-F^{\downarrow}+\sigma T^{4},
\end{aligned}
$$

with $\sigma$ the Stefan-Boltzmann constant. To close the system, the fluxes at the surface and at the top of the atmosphere are such that

$$
\begin{gathered}
F^{\uparrow}\left(D=D_{0}\right)=\sigma \mathrm{SST}^{4}, \\
F^{\downarrow}(D=0)=0 .
\end{gathered}
$$

This choice of boundary conditions is different from Frierson et al. (2006) and allows us to constrain the forcing to almost entirely depend on the SST field.

We prescribe total optical depth $D$ to be dependent only on latitude $y$ and pressure $p$. The surface optical depth $D_{0}\left(y, p=p_{0}\right)=D_{0}(y)$ is such that

$$
D_{0}(y)=D_{\text {eq }} \cos ^{2}\left(\frac{\pi y}{2 L_{y}}\right)+D_{\text {pole }} \sin ^{2}\left(\frac{\pi y}{2 L_{y}}\right) .
$$

Then we separate optical depths in the troposphere and stratosphere by introducing $D_{T}$ and $D_{S}$ such that

$$
D=\max \left(D_{T}, D_{S}\right)
$$

with

$$
\begin{aligned}
D_{S}(y, p)= & \frac{1}{4} \frac{p}{p_{0}} D_{0}(y) \\
D_{T}(y, p)= & \left(1+D_{0}\right)\left(\frac{p}{p_{0}}\right)^{4 \kappa} \\
& \times\left[1-\frac{\Delta \theta}{\alpha \overline{\mathrm{SST}}} \log \left(\frac{p}{p_{0}}\right)\right]^{4}-1 .
\end{aligned}
$$

Table 1 summarizes the values of the various parameters.

In (B8), $\overline{\mathrm{SST}}$ is the zonal average of SST and

$$
\alpha=\left(\frac{1+D_{0}}{2+D_{0}}\right)^{1 / 4}
$$

Here, $D_{S}$ is larger than $D_{T}$ in the highest atmospheric layers, and transition from one expression to the other roughly sets the height of the tropopause in our experiment.

In the model, the diabatic term due to radiative forcing is expressed in the temperature equation as

$$
R=\frac{1}{\rho C_{p}} \frac{\partial\left(F^{\uparrow}-F^{\downarrow}\right)}{\partial z} .
$$

To understand the nature of this forcing, we can compute the potential temperature at radiative equilibrium $\theta_{\mathrm{Rad}}$, that is, when $R=0$. Below the tropopause, 
$D(y, p)=D_{T}(y, p)$ and using (B1)-(B5) and (B8), we obtain

$$
\theta_{\mathrm{Rad}}(x, y)=\alpha \operatorname{SST}(x, y)-\Delta \theta \log \left(\frac{p}{p_{0}}\right) \frac{\operatorname{SST}(x, y)}{\operatorname{SST}(y)} .
$$

Since $\alpha$ is weakly dependent on $y$ (ranging between 0.92 and 0.96 ), the gray radiation scheme relaxes temperature toward a profile whose meridional gradient is proportional to $\partial \overline{\mathrm{SST}} / \partial y$ in zonal mean. Such a profile is similar to the radiative equilibrium of Held and Suarez (1994).

To ensure that the boundary layer response does not depend on radiative parameterization choices, two other sensitivity runs were done. In the first one, $\overline{\operatorname{SST}}(y)$ was replaced by $\operatorname{SST}(x, y)$ in (B8), while in the second one, $\operatorname{SST}(x, y)$ was replaced by $\overline{\operatorname{SST}}(y)$ in (B3). While radiative fluxes act either as an additional heat source or sink at the scale of the oceanic eddies in each experiment, the impact on the main heat budget remained small, and no major differences were obtained concerning the results of this paper.

\section{REFERENCES}

Ayet, A., and J.-L. Redelsperger, 2019: An analytical study of the atmospheric boundary layer flow and divergence over a SST front. Quart. J. Roy. Meteor. Soc., https://doi.org/ 10.1002/qj.3578, in press.

Bourras, D., G. Reverdin, H. Giordani, and G. Caniaux, 2004: Response of the atmospheric boundary layer to a mesoscale oceanic eddy in the northeast Atlantic. J. Geophys. Res., 109, D18114, https://doi.org/10.1029/2004JD004799.

Brachet, S., F. Codron, Y. Feliks, M. Ghil, H. Le Treut, and E. Simonnet, 2012: Atmospheric circulations induced by a midlatitude SST front: A GCM study. J. Climate, 25, 18471853, https://doi.org/10.1175/JCLI-D-11-00329.1.

Byrne, D., L. Papritz, I. Frenger, M. Münnich, and N. Gruber, 2015: Atmospheric response to mesoscale sea surface temperature anomalies: Assessment of mechanisms and coupling strength in a high-resolution coupled model over the South Atlantic. J. Atmos. Sci., 72, 1872-1890, https://doi.org/10.1175/JAS-D14-0195.1.

Chelton, D. B., and Coauthors, 2001: Observations of coupling between surface wind stress and sea surface temperature in the eastern tropical Pacific. J. Climate, 14, 1479-1498, https://doi.org/ 10.1175/1520-0442(2001)014<1479:OOCBSW>2.0.CO;2.

_ M. G. Schlax, M. H. Freilich, and R. F. Milliff, 2004: Satellite measurements reveal persistent small-scale features in ocean winds. Science, 303, 978-983, https://doi.org/10.1126/ science.1091901.

Chen, L., Y. Jia, and Q. Liu, 2017: Oceanic eddy-driven atmospheric secondary circulation in the winter Kuroshio Extension region. J. Oceanogr., 73, 295-307, https://doi.org/10.1007/ s10872-016-0403-z.

Dewar, W. K., and G. R. Flierl, 1987: Some effects of the wind on rings. J. Phys. Oceanogr., 17, 1653-1667, https://doi.org/10.1175/ 1520-0485(1987)017<1653:SEOTWO > 2.0.CO;2.

Doglioli, A. M., B. Blanke, S. Speich, and G. Lapeyre, 2007: Tracking coherent structures in a regional ocean model with wavelet analysis: Application to Cape Basin eddies. J. Geophys. Res., 112, C05043, https://doi.org/10.1029/2006JC003952.

Feliks, Y., M. Ghil, and E. Simonnet, 2004: Low-frequency variability in the midlatitude atmosphere induced by an oceanic thermal front. J. Atmos. Sci., 61, 961-981, https://doi.org/ 10.1175/1520-0469(2004)061<0961:LVITMA>2.0.CO;2.

Foussard, A., G. Lapeyre, and R. Plougonven, 2019: Storm tracks response to oceanic eddies in idealized atmospheric simulations. J. Climate, 32, 445-463, https://doi.org/10.1175/JCLI-D18-0415.1.

Frenger, I., N. Gruber, R. Knutti, and M. Münnich, 2013: Imprint of Southern Ocean eddies on winds, clouds and rainfall. Nat. Geosci., 6, 608-612, https://doi.org/10.1038/ngeo1863.

Frierson, D. M., I. M. Held, and P. Zurita-Gotor, 2006: A grayradiation aquaplanet moist GCM. Part I: Static stability and eddy scale. J. Atmos. Sci., 63, 2548-2566, https://doi.org/ 10.1175/JAS3753.1.

Hayes, S., M. McPhaden, and J. Wallace, 1989: The influence of sea-surface temperature on surface wind in the eastern equatorial Pacific: Weekly to monthly variability. J. Climate, 2, 1500-1506, https://doi.org/10.1175/1520-0442(1989)002<1500: TIOSST $>2.0 . \mathrm{CO} ; 2$.

Held, I. M., and M. J. Suarez, 1994: A proposal for the intercomparison of the dynamical cores of atmospheric general circulation models. Bull. Amer. Meteor. Soc., 75, 1825-1830, https://doi.org/10.1175/1520-0477(1994)075<1825:APFTIO> 2.0.CO;2.

Hong, S.-Y., Y. Noh, and J. Dudhia, 2006: A new vertical diffusion package with an explicit treatment of entrainment processes. Mon. Wea. Rev., 134, 2318-2341, https://doi.org/10.1175/ MWR3199.1.

Kain, J. S., and J. M. Fritsch, 1993: Convective parameterization for mesoscale models: The Kain-Fritsch scheme. The Representation of Cumulus Convection in Numerical Models, K. A. Emanuel and D. J. Raymond, Eds., Amer. Meteor. Soc., 165-170.

Kessler, E., 1969: On the Distribution and Continuity of Water Substance in Atmospheric Circulation. Meteor. Monogr., No. 32, Amer. Meteor. Soc., 84 pp.

Kilpatrick, T., N. Schneider, and B. Qiu, 2014: Boundary layer convergence induced by strong winds across a midlatitude SST front. J. Climate, 27, 1698-1718, https://doi.org/10.1175/JCLID-13-00101.1.

,-- , and -2016 : Atmospheric response to a midlatitude SST front: Alongfront winds. J. Atmos. Sci., 73, 3489-3509, https://doi.org/10.1175/JAS-D-15-0312.1.

Lambaerts, J., G. Lapeyre, R. Plougonven, and P. Klein, 2013: Atmospheric response to sea surface temperature mesoscale structures. J. Geophys. Res. Atmos., 118, 9611-9621, https:// doi.org/10.1002/jgrd.50769.

Lapeyre, G., 2017: Surface quasi-geostrophy. Fluids, 2, 7, https:// doi.org/10.3390/fluids2010007.

_ , and P. Klein, 2006: Impact of the small-scale elongated filaments on the oceanic vertical pump. J. Mar. Res., 64, 835-851, https://doi.org/10.1357/002224006779698369.

Lindzen, R. S., and S. Nigam, 1987: On the role of sea surface temperature gradients in forcing low-level winds and convergence in the tropics. J. Atmos. Sci., 44, 2418-2436, https:// doi.org/10.1175/1520-0469(1987)044<2418:OTROSS $>$ 2.0.CO;2.

Liu, J.-W., and S.-P. Zhang, 2013: Two types of surface wind response to the East China Sea Kuroshio front. J. Climate, 26, 8616-8627, https://doi.org/10.1175/JCLI-D-12-00092.1. 
Ma, J., H. Xu, C. Dong, P. Lin, and Y. Liu, 2015: Atmospheric responses to oceanic eddies in the Kuroshio Extension region. J. Geophys. Res. Atmos., 120, 6313-6330, https://doi.org/ 10.1002/2014JD022930.

Minobe, S., A. Kuwano-Yoshida, N. Komori, S.-P. Xie, and R. J. Small, 2008: Influence of the Gulf Stream on the troposphere. Nature, 452, 206-209, https://doi.org/10.1038/nature06690.

Moulin, A., and A. Wirth, 2016: Momentum transfer between an atmospheric and an oceanic layer at the synoptic and the mesoscale: An idealized numerical study. Bound.-Layer Meteor., 160, 551-568, https://doi.org/10.1007/s10546-016-0153-x.

Nakanishi, M., and H. Niino, 2004: An improved Mellor-Yamada level-3 model with condensation physics: Its design and verification. Bound.-Layer Meteor., 112, 1-31, https://doi.org/ 10.1023/B:BOUN.0000020164.04146.98.

O'Neill, L. W., D. B. Chelton, and S. K. Esbensen, 2003: Observations of SST-induced perturbations of the wind stress field over the Southern Ocean on seasonal timescales. J. Climate, 16, 2340-2354, https://doi.org/10.1175/2780.1.

,-- , and -2012 : Covariability of surface wind and stress responses to sea surface temperature fronts. J. Climate, 25, 5916-5942, https://doi.org/10.1175/JCLI-D-11-00230.1.

— T. Taack, D. B. Chelton, and E. Skyllingstad, 2017: The Gulf Stream convergence zone in the time-mean winds. J. Atmos. Sci., 74, 2383-2412, https://doi.org/10.1175/JAS-D-16-0213.1.

Oerder, V., F. Colas, V. Echevin, S. Masson, and F. Lemarié, 2018: Impacts of the mesoscale ocean-atmosphere coupling on the Peru-Chile ocean dynamics: The current-induced wind stress modulation. J. Geophys. Res. Oceans, 123, 812-833, https:// doi.org/10.1002/2017JC013294.

Park, K., P. Cornillon, and D. L. Codiga, 2006: Modification of surface winds near ocean fronts: Effects of Gulf Stream rings on scatterometer (QuikSCAT, NSCAT) wind observations. J. Geophys. Res., 111, C03021, https://doi.org/10.1029/ 2005JC003090.

Perlin, N., S. P. De Szoeke, D. B. Chelton, R. M. Samelson, E. D. Skyllingstad, and L. W. O'Neill, 2014: Modeling the atmospheric boundary layer wind response to mesoscale sea surface temperature perturbations. Mon. Wea. Rev., 142, 4284-4307, https://doi.org/10.1175/MWR-D-13-00332.1.

Plougonven, R., A. Foussard, and G. Lapeyre, 2018: Comments on "The Gulf Stream convergence zone in the time-mean winds." J. Atmos. Sci., 75, 2139-2149, https://doi.org/10.1175/JAS-D17-0369.1.

Putrasahan, D. A., A. J. Miller, and H. Seo, 2013: Isolating mesoscale coupled ocean-atmosphere interactions in the Kuroshio Extension region. Dyn. Atmos. Oceans, 63, 60-78, https:// doi.org/10.1016/j.dynatmoce.2013.04.001.

Renault, L., M. J. Molemaker, J. C. McWilliams, A. F. Shchepetkin, F. Lemarié, D. Chelton, S. Illig, and A. Hall, 2016: Modulation of wind work by oceanic current interaction with the atmosphere. J. Phys. Oceanogr., 46, 1685-1704, https:// doi.org/10.1175/JPO-D-15-0232.1.

Samelson, R., E. Skyllingstad, D. Chelton, S. Esbensen, L. O’Neill, and N. Thum, 2006: On the coupling of wind stress and sea surface temperature. J. Climate, 19, 1557-1566, https://doi.org/ 10.1175/JCLI3682.1.

Schneider, N., and B. Qiu, 2015: The atmospheric response to weak sea surface temperature fronts. J. Atmos. Sci., 72, 3356-3377, https://doi.org/10.1175/JAS-D-14-0212.1.

Shimada, T., and S. Minobe, 2011: Global analysis of the pressure adjustment mechanism over sea surface temperature fronts using AIRS/Aqua data. Geophys. Res. Lett., 38, L06704, https://doi.org/10.1029/2010GL046625.

Skamarock, W., and Coauthors, 2008: A description of the Advanced Research WRF version 3. NCAR Tech. Note NCAR/ TN-475+STR, 113 pp., https://doi.org/10.5065/D68S4MVH.

Skyllingstad, E. D., D. Vickers, L. Mahrt, and R. Samelson, 2007: Effects of mesoscale sea-surface temperature fronts on the marine atmospheric boundary layer. Bound.-Layer Meteor., 123, 219-237, https://doi.org/10.1007/s10546-006-9127-8.

Small, R., and Coauthors, 2008: Air-sea interaction over ocean fronts and eddies. Dyn. Atmos. Oceans, 45, 274-319, https:// doi.org/10.1016/j.dynatmoce.2008.01.001.

Song, Q., D. B. Chelton, S. K. Esbensen, N. Thum, and L. W. O'Neill, 2009: Coupling between sea surface temperature and low-level winds in mesoscale numerical models. J. Climate, 22 , 146-164, https://doi.org/10.1175/2008JCLI2488.1.

Spall, M. A., 2007: Midlatitude wind stress-sea surface temperature coupling in the vicinity of oceanic fronts. J. Climate, 20, 3785-3801, https://doi.org/10.1175/JCLI4234.1.

Stern, M. E., 1965: Interaction of a uniform wind stress with a geostrophic vortex. Deep-Sea Res. Oceanogr. Abstr., 12, 355367, https://doi.org/10.1016/0011-7471(65)90007-0.

Stull, R. B., 1989: An Introduction to Boundary Layer Meteorology. Kluwer Academic, 666 pp.

Takatama, K., and N. Schneider, 2017: The role of back pressure in the atmospheric response to surface stress induced by the Kuroshio. J. Atmos. Sci., 74, 597-615, https://doi.org/10.1175/ JAS-D-16-0149.1.

_ S. Minobe, M. Inatsu, and R. J. Small, 2015: Diagnostics for near-surface wind response to the Gulf Stream in a regional atmospheric model. J. Climate, 28, 238-255, https://doi.org/ 10.1175/JCLI-D-13-00668.1.

Wallace, J. M., T. Mitchell, and C. Deser, 1989: The influence of sea-surface temperature on surface wind in the eastern equatorial Pacific: Seasonal and interannual variability. J. Climate, 2, 1492-1499, https://doi.org/10.1175/1520-0442(1989) 002<1492:TIOSST $>2.0$. CO;2.

Xie, S.-P., 2004: Satellite observations of cool ocean-atmosphere interaction. Bull. Amer. Meteor. Soc., 85, 195-208, https:// doi.org/10.1175/BAMS-85-2-195. 